\title{
Neuronal Rac1 Is Required for Learning-Evoked Neurogenesis
}

\author{
Ursula Haditsch, ${ }^{1}$ Matthew P. Anderson, ${ }^{1}$ Julia Freewoman, ${ }^{1}$ Branden Cord, ${ }^{1}$ Harish Babu, ${ }^{1}$ Cord Brakebusch, ${ }^{2}$ \\ and Theo D. Palmer ${ }^{1}$ \\ ${ }^{1}$ Institute for Stem Cell Biology and Regenerative Medicine, Stanford University, Stanford, California 94305 and ${ }^{2}$ Biotech Research and Innovation Centre, \\ University of Copenhagen, DK-2200 Copenhagen, Denmark
}

\begin{abstract}
Hippocampus-dependent learning and memory relies on synaptic plasticity as well as network adaptations provided by the addition of adult-born neurons. We have previously shown that activity-induced intracellular signaling through the Rho family small GTPase Rac1 is necessary in forebrain projection neurons for normal synaptic plasticity in vivo, and here we show that selective loss of neuronal Racl also impairs the learning-evoked increase in neurogenesis in the adult mouse hippocampus. Earlier work has indicated that experience elevates the abundance of adult-born neurons in the hippocampus primarily by enhancing the survival of neurons produced just before the learning event. Loss of Racl in mature projection neurons did reduce learning-evoked neurogenesis but, contrary to our expectations, these effects were not mediated by altering the survival of young neurons in the hippocampus. Instead, loss of neuronal Racl activation selectively impaired a learning-evoked increase in the proliferation and accumulation of neural precursors generated during the learning event itself. This indicates that experience-induced alterations in neurogenesis can be mechanistically resolved into two effects: (1) the well documented but Rac1-independent signaling cascade that enhances the survival of young postmitotic neurons; and (2) a previously unrecognized Racl-dependent signaling cascade that stimulates the proliferative production and retention of new neurons generated during learning itself.
\end{abstract}

\section{Introduction}

Ras-related C3 botulinum toxin substrate 1 (Rac1), a member of the small Rho family of GTPases, is involved in several aspects of neural development including cell migration, neuronal morphogenesis, axon growth and guidance, dendrite elaboration, synapse formation, and plasticity (Nakayama et al., 2000; Luo, 2000; Tashiro and Yuste, 2008). In mature neurons, activation of the NMDA receptor increases the amount of GTP-bound Racl and causes translocation of Racl from the cytosol to the membrane (Tejada-Simon et al., 2006). This facilitates the Rac1-dependent reorganization of the neuronal cytoskeleton and synapse morphology during activity-dependent plasticity.

Loss of Racl in neurons alters dendritic spine size, reduces spine density, and impairs traditional measures of plasticity, such as hippocampal long-term potentiation (Haditsch et al., 2009). Not surprisingly, neuronal Racl activation is important for episodic learning and memory (Diana et al., 2007; Martinez et al.,

Received June 20, 2012; revised June 10, 2013; accepted June 12, 2013.

Author contributions: U.H. and T.D.P. designed research; U.H., M.P.A., J.F., and B.C. performed research; C.B. contributed unpublished reagents/analytic tools; U.H. and M.P.A. analyzed data; U.H., H.B., and T.D.P. wrote the paper.

This work was supported by grants to T.D.P. from the National Institutes of Health (R01 MH071472, R21 NS050549, and R01 NS045113) and the California Institute for Regenerative Medicine (RC1-00134).

The sponsors had no role in study design, data collection and analysis, decision to publish, or preparation of this manuscript.

Correspondence should be addressed to either Ursula Haditsch or Theo Palmer, Institute for Stem Cell Biology and Regenerative Medicine, The Lorry I. Lokey Stem Cell Research Building, 265 Campus Drive, Stanford University, Stanford, CA 94305, E-mail: ursula.haditsch@stanford.edu or tpalmer@stanford.edu.

DOI:10.1523/JNEUROSCI.2939-12.2013

Copyright $\odot 2013$ the authors $\quad 0270-6474 / 13 / 3312229-13 \$ 15.00 / 0$
2007; Haditsch et al., 2009), a type of working memory that relies on the hippocampal dentate gyrus (DG) to integrate and encode complex associative information (Sutherland et al., 1983; Xavier et al., 1999; Jeltsch et al., 2001).

It is also known that neurogenesis in the DG contributes to learning and memory (Aimone et al., 2006; Wojtowicz, 2008; Shors, 2008; Deng et al., 2010; Castilla-Ortega et al., 2011) and that experience-induced NMDA signaling in hippocampal neurons increases the retention of new neurons in the DG (Deisseroth et al., 2004; Ge et al., 2007; Tronel et al., 2010; Curlik and Shors, 2011). It is thought that experience-induced increases in new neuron abundance occurs in part by activity-dependent transcriptional events that influence both synaptic function and survival of new neurons (Sairanen et al., 2005; Ma et al., 2009a,b, 2010; Lee and Son, 2009).

Given the importance of Racl in the neuronal response to NMDA and its role in regulation of gene transcription (Minden et al., 1995; Yang et al., 2004; Esufali and Bapat, 2004; Kwei et al., 2006; Buongiorno et al., 2008), we predicted that selective loss of Rac1 signaling in mature projection neurons would alter neurogenesis. Surprisingly, loss of Racl had no effect on basal neurogenesis, nor did it impact the experience-evoked increase in young neuron survival. However, the net number of new neurons was reduced in Racl mutant animals. We subsequently discovered that neuronal Rac1 was selectively required for a learningevoked increase in the proliferative production of new neurons during learning. Loss of neuronal Racl also attenuated the learning-induced upregulation of activity-dependent genes such as Gadd45b and brain-derived neurotrophic factor (BDNF), and 
resulted in increased expression of transforming growth factor- $\beta 1$ (TGF- $\beta 1$ ) and p27 Kip1.

These data suggest that the experience-evoked increase in the abundance of newborn neurons in the adult hippocampus is caused by Racl-independent effects that enhance survival of young postmitotic neurons as well as Rac1-dependent signaling that promotes an increase in proliferation during learning itself.

\section{Materials and Methods}

Mice. Conditional Rac1 mutant mice (CaMKII $\alpha-\mathrm{Cre}^{+/+}: \mathrm{Racl}^{1 \mathrm{lox} / \mathrm{lox}}$ ) and their control littermates $\left(\mathrm{Cre}^{-1+}: \mathrm{Racl}^{\text {lox/wt }}\right.$ or $\mathrm{Cre}^{-/-}: \mathrm{Racl}^{\text {lox/lox }}$ ) mice have previously been described (Haditsch et al., 2009). To visualize Cre-mediated recombination, mice carried either the Z/EG (Novak et al., 2000) or the R26-EGFP (Soriano, 1999) reporter allele. All experiments were performed on mutant and control male mice that were 3-7 months old. All mice were housed under standard microisolator housing in a $12 \mathrm{~h}$ (07:00-19:00) light/dark cycle at $22^{\circ} \mathrm{C}$ with food and water available ad libitum. All animal studies were performed in accordance with federal guidelines and were reviewed and approved by the Stanford Institutional Animal Care and Use Committee.

Bromodeoxyuridine, chlorodeoxyuridine, and iododeoxyuridine injections and tissue preparation. Dividing cells before learning were labeled with chlorodeoxyuridine (CldU, Sigma-Aldrich). CldU was dissolved to a final concentration of $10 \mathrm{mg} / \mathrm{ml}$ in warm saline, and mice were injected intraperitoneally once a day $(50 \mathrm{mg} / \mathrm{kg})$ in the afternoon $(2 \mathrm{~h}$ before the onset of the dark cycle) for $7 \mathrm{~d}$. To label dividing cells during learning, bromodeoxyuridine (BrdU, Sigma-Aldrich) or iododeoxyuridine (IdU; Sigma-Aldrich) were dissolved in saline to a final concentration of 10 $\mathrm{mg} / \mathrm{ml}$ or $12 \mathrm{mg} / \mathrm{ml}$, respectively, to ensure equal molarity. To assess proliferation, mice received a single injection of $100 \mathrm{mg} / \mathrm{kg}$ on day 7 right after learning and were perfused $24 \mathrm{~h}$ later. To determine the short-term survival of newborn cells, mice were injected with $50 \mathrm{mg} / \mathrm{kg}$ on days 7 and 8 right after the training and were perfused $11 \mathrm{~d}$ later.

Histology and stereology. For histological analysis mice were deeply anesthetized with ketamine/xylazine (100 and $7 \mathrm{mg} / \mathrm{kg}$, respectively), then transcardially perfused with cold saline, followed by $4 \%$ cold paraformaldehyde (PFA) in $0.1 \mathrm{~m}$ phosphate buffer. Brains were collected and postfixed overnight in $4 \% \mathrm{PFA}$ at $4^{\circ} \mathrm{C}$, then cryoprotected in $30 \%$ sucrose and stored at $4^{\circ} \mathrm{C}$. Free-floating $40 \mu \mathrm{m}$ sections were collected on a freezing sledge microtome (Leica) and stored in tissue cryoprotectant solution at $-20^{\circ} \mathrm{C}$.

Floating sections were prepared for BrdU/CldU/IdU detection by incubation in $2 \mathrm{~N} \mathrm{HCl}$ for $30 \mathrm{~min}$ at $37^{\circ} \mathrm{C}$ and washing in Tris-buffered saline (TBS), $\mathrm{pH} 7.5$, for $10 \mathrm{~min}$. Sections were incubated in TBS with $0.3 \%$ Triton X-100 and $1 \%$ normal donkey serum at $4^{\circ} \mathrm{C}$ overnight containing the following primary antibodies: rat anti-BrdU (1:500, for CldU and BrdU detection; Accurate Chemical), mouse anti-BrdU (1:500, for IdU detection; BD Biosciences), goat anti-doublecortin (1:500; Santa Cruz Biotechnology), mouse anti-NeuN (1:200, Millipore Bioscience Research Reagents), mouse anti- $\beta$-galactosidase ( $\beta$-gal; $1: 100$; Invitrogen), rabbit or mouse anti-GFP (1:500; Invitrogen), sheep anti-BDNF (1:200; Millipore Bioscience Research Reagents), rabbit anti-Rac1 (1: 100; Santa Cruz Biotechnology), anti-rabbit postsynaptic density (PSD)-95 (1:200; Zymed), mouse anti-p27 Kip1 (1:200; Abcam), rabbit anti-Ki67 (1:200; Abcam), rabbit anti-TrkB (1:200; Abcam), and rabbit anti-Gadd45b biotinylated (1:200; Bioss Antibodies). Species-specific fluorescent secondary antibodies from donkey conjugated with fluorescein isothiocyanate (FITC), Cy3, pacific orange, or Cy5 were obtained from Jackson ImmunoResearch and used at 1:500. Fluorescent signals were detected using a confocal microscope (Zeiss LSM 710 Meta). All counts were performed using multitrack configurations with a $40 \times$ objective and electronic zoom of 2. Colocalization of fluorescent signals was determined by optical sectioning in the $Z$-plane. Images of a single $Z$-plane were analyzed with the colocalization tool provided by ZEN2011 software from Zeiss. For the phenotypic analysis of BrdU-, IdU-, or CldU-positive cells, 100 or more cells per animal were assessed for colocalization with Dcx and NeuN.
The total numbers of BrdU/CldU/IdU positive-labeled cells per granular layer and subgranular zone of the DG were evaluated by peroxidasediaminobenzidine histochemical staining. Both hemispheres were examined in every twelfth section throughout the entire DG. Positive cells were scored under light microscopy using Stereo Investigator (MicroBrightField) software and the Fractionator method.

PSD-95 density. The analysis of PSD has been previously described (Haditsch et al., 2009). Enhanced green fluorescent protein (GFP)positive apical dendrites of CA1 neurons $(25-100 \mathrm{~mm}$ from the cell body) and in the molecular layer of the DG were analyzed. Serial confocal images ( $Z$-steps of $0.5 \mu \mathrm{m}$ ) were obtained for Cy3 (detecting PSD-95) and FITC (detecting EGFP-labeled dendrites) fluorescence with a $63 \times$ objective and a digital zoom factor of 2 . The number of PSD-95 clusters per dendrite was counted using the LSM Image Browser software (Zeiss).

Quantitative reverse transcription-PCR. DGs were microdissected as previously described (Babu et al., 2011). The excised tissue dissociated into a single-cell suspension and fractionated by centrifugation in $22 \%$ Percoll into pelleted immature neural stem and neural progenitor cells (NPCs) and buoyant differentiated neurons, myelin, and extracellular matrix. Cell fractions were washed and RNA prepared for quantitative reverse transcription (qRT)-PCR using CellsDirect One-Step qRT-PCR Kit (Invitrogen) or SuperScript III First-Strand Synthesis System for RTPCR (Invitrogen). Gene-specific fluorescence-labeled TaqMan primers were purchased from Applied Biosystems and qPCR was performed with Fluidigm's BioMark real-time PCR system using Fluidigm 96.96 Dynamic Array chips (Fluidigm).

Bisulfite sequencing and analysis of DNA methylation in the adult DG. Genomic DNA was extracted from microdissected DGs with the AllPrep DNA/RNA/Protein Mini kit (Qiagen). Genomic DNA ( $1 \mu \mathrm{g})$ was bisulfite converted using commercial reagents (EpiTect Bisulfite kit; Qiagen). The converted DNA was purified and $50 \mathrm{ng}$ was used as a template in the $50 \mu$ l PCR using KAPA Taq Polymerase (KAPA Biosystems). Primers were designed to cover seven $\mathrm{CpG}$ sites on the $\mathrm{BDNF}$ promoter region IX: 5' -GTTGGAGATGGGATTTTT-3', biotinylated 5' -TCCTTTCAAATCAACAACATAA- $3^{\prime}$. Changes in DNA methylation were revealed by pyrosequencing (PyroMark 24; Qiagen) with two sequencing primers: 5'-AGTTTTTTAAGTTTTTTTATGAGA-3' and 5'-AGGAAAAGGTTTTTTTTAGTA-3'.

Morris water maze. The delayed matching-to place (DMP) task was performed as previously described (Haditsch et al., 2009) using 3- to 7-month-old male mutant and control littermates. Training for the "learner" groups (see Figs. 3, 5) consisted of 12 training trials per day with 5 min intertrial interval (ITI) on days $1-7$ and six training trials $1 \mathrm{~h}$ apart for days 8 and 9 . In the evening of days 7 and 8 , mice were injected with BrdU or IdU (50 mg/kg, i.p.). The Cx546-treated groups received one daily intraperitoneal injection of Cx546 (30 mg/kg; Sigma-Aldrich) 30 min before the training on days $4-8$. Cx546 was first dissolved in dimethylsulfoxide and then diluted in 10\% 2-hydroxypropyl-cyclodextrin (Sigma-Aldrich) in saline. Training for the runner-learner groups (see Fig. 7) consisted of 10 training trials for $8 \mathrm{~d}$ ( 5 min ITI) and 6 training trials for days 9 and 10 ( $1 \mathrm{~h} \mathrm{ITI).} \mathrm{The} \mathrm{experimenter} \mathrm{was} \mathrm{blind} \mathrm{to} \mathrm{genotype}$ for all behavioral tests.

Voluntary running setup. Two to three mice were housed for $14 \mathrm{~d}$ in standard-size cages containing a running wheel (Super Pet Run-Around Exercise Wheels; PetSmart). Mice were monitored daily to confirm running activity. The last $7 \mathrm{~d}$ of running the mice received a daily CldU injection $(50 \mathrm{mg} / \mathrm{kg}) 2 \mathrm{~h}$ before the beginning of the active (dark) phase.

Data analyses. Statistical analysis was performed using Statistica software (StatSoft). In repeated-measures comparisons conducted in the DMP task, the dependent variables were analyzed using ANOVA with genotype as the between-subject factor and session and as within-subject factors. Statistical significant effects revealed by ANOVA were explored using Newman-Keuls post hoc test. Mean \pm SEM is presented.

\section{Results}

\section{Strategy for selective ablation of Racl in postmitotic forebrain projection neurons}

We have previously described the conditional deletion of Racl in forebrain projection neurons (Haditsch et al., 2009). In this 
A
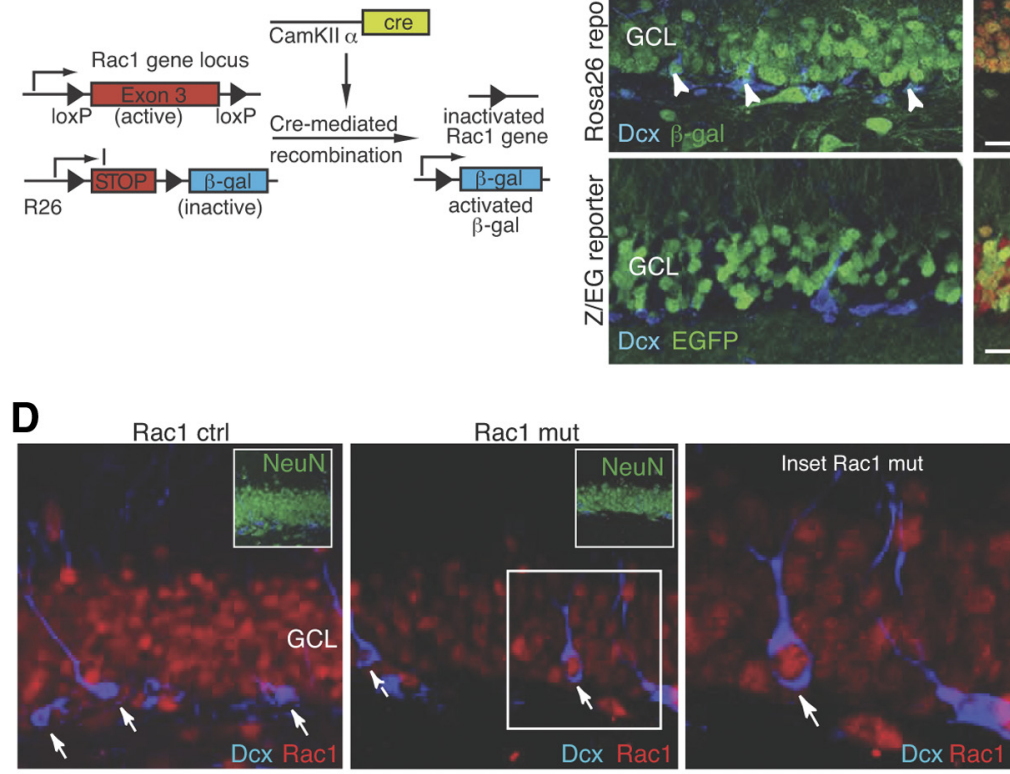

B

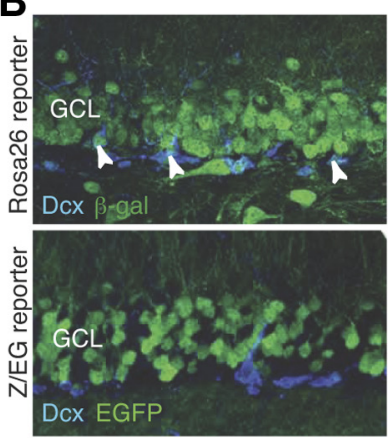

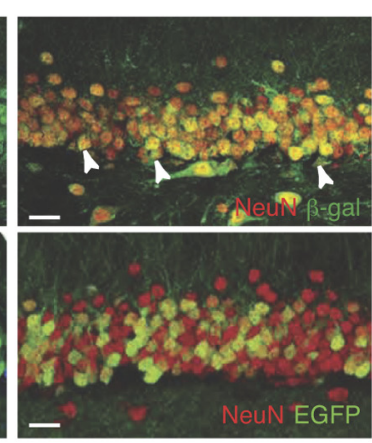

E Postmitotic cells

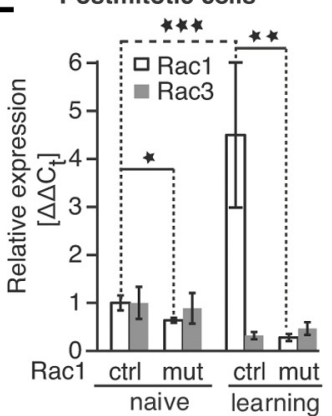

C

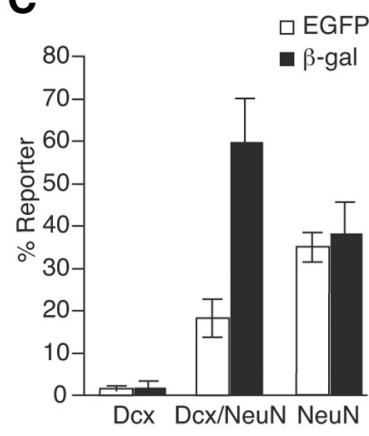

F Progenitor cells

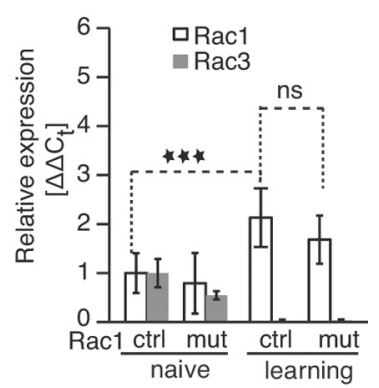

Figure 1. Conditional ablation of Rac1 in postmitotic neurons of the DG. A, Schematic representation: conditional loss of Rac1 was achieved via CaMKIl $\alpha$-driven Cre-mediated ablation of exon 3 of rac1 (Chrostek et al., 2006). At the same time recombined cells were visualized by Cre-mediated induction of a conditional reporter such as $\beta$-gal. $\boldsymbol{B}$, $\beta$-gal (Rosa26 reporter mouse, top; Soriano, 1999) and EGFP (Z/EG, bottom; Novak et al., 2000) expression in the granular cell layer (GCL) of the DG. Reporter-positive green cells colabeled with the postmitotic neuronal marker NeuN (red, arrowheads). Scale bars, $20 \mu \mathrm{m}$. C, Percentage of doublecortin (Dcx), Dcx/NeuN, and NeuN-positive cells that express the reporters (GFP or $\beta$-gal). Less than $1 \%$ of Dcx ${ }^{+}$precursor cells colabeled with either reporter. Reporter expression was detected in postmitotic $\mathrm{Dcx} / \mathrm{NeuN}{ }^{+}$intermediate neurons and mature $\mathrm{NeuN}^{+}$neurons. $\boldsymbol{D}$, Rac1 protein expression in the $\mathrm{GCL}$ of Rac1 control mice (left) and Rac1 mutant mice (right). Rac1 (red) was abundantly expressed in NeuN-positive GCL neurons and in Dcx ${ }^{+}$NPCs (blue, arrows). Rac1 expression in Rac1 mutant mice was downregulated in the mature neurons but still present in $\mathrm{Dcx}{ }^{+}$neurons, as seen in higher magnification on the right. $\boldsymbol{E}$, Relative Rac1 and Rac3 mRNA levels in cell fractions enriched for mature neurons of the hippocampus. Significantly lower Rac1 expression is seen in Rac1 mutant mature neurons of naive animals (controls, $n=8$; mutants, $n=6$; ANOVA, $F_{(1,12)}=6.03,{ }^{*} p<0.05$ ). Rac3 expression was also evaluated as an internal control and no change in expression was detected. Rac1 expression was significantly upregulated during $7 \mathrm{~d}$ of learning in Rac1 control mice but remained low in Rac1 mutant learners ( $n>5$ for all groups of mice; ANOVA with post hoc test, ${ }^{* *} p<0.01,{ }^{* * *} p<0001$; overall genotype effect, two-way ANOVA, $\left.F_{(9,44)}=5.24 ; p<0.001\right)$. $F$, Significant upregulation of Rac1 mRNA levels is also detected in cell fractions enriched for NPCs of the hippocampus during $7 \mathrm{~d}$ of learning in Rac1 control mice (control naives, $n=10$; control learners, $n=5$; ANOVA with post hoc test, $p<0001)$. No significant differences were detected in Rac1 expression between Rac1 control and mutant mice. ${ }^{*} p<0.05$, ${ }^{* * *} p<0.001$, ns, not significant.

mouse model, cre is driven by a CaMKII $\alpha$ promoter (Fig. 1A). Excision and activation of reporter genes is observed exclusively in forebrain projection neurons. Excision does not occur during fetal development but begins at $\sim 2-3$ weeks of age and the fraction of reporter-positive projection neurons increases to a maximum at $\sim 2$ months of age (Schweizer et al., 2003). After 2 months of age, Cre-dependent $\beta$-gal or EGFP reporter expression is observed in $>40 \%$ of $\mathrm{NeuN}^{+}$neurons of the DG (Fig. $1 B, C)$. The hippocampal formation also contains progenitor cells and newborn neurons. CaMKII $\alpha$ and $\beta$-gal or EGFP reporter expression is observed in $<1 \%$ of immature Dcx-expressing neuroblasts but is detected in postmitotic young neurons that are positive for both Dcx and NeuN (Fig. 1C). Immunoreactivity for Rac1 protein is notably reduced or absent in mature $\mathrm{NeuN}^{+}$granule layer neurons in the DG (Fig. 1D) as well as in the CA1 region of the hippocampus (Haditsch et al., 2009) but unaffected in stem cells and $\mathrm{Dcx}^{+}$progenitor cells that reside within the subgranular zone of the DG (Fig. 1D).

To evaluate the abundance of Racl mRNA in the hippocampus, cells from the hippocampal formations of naive mice or mice trained for $7 \mathrm{~d}$ in the DMP water maze task were fractionated by density centrifugation into immature NPCs or mature neurons and glia (Palmer et al., 2001; Babu et al., 2007). qRT-PCR confirmed a reduction in Racl expression in naive Racl mutant animals and absence of a learning-evoked increase in Racl fol- lowing learning (Fig. 1E). Learning also evoked an increase in Rac1 transcripts in neuronal NPCs (Fig. $1 F$ ) but transcript abundance was unaffected in Racl mutants, indicating that the interruption of experience-evoked Rac1-dependent responses occurs selectively in mature neurons but not in NPCs. Rac3 expression did not differ between Racl mutant and control mice.

\section{Loss of neuronal Racl has no effect on basal neurogenesis}

To determine the effect of conditional loss of neuronal Racl on baseline hippocampal neurogenesis, control and Racl mutant mice were injected with BrdU for $7 \mathrm{~d}$. One week after the last injection of the BrdU, the abundance of BrdU-labeled cells was assessed by immunofluorescent staining and stereological analysis (Fig. $2 A, B$ ). Loss of neuronal Racl had no effect on the total number of $\mathrm{BrdU}^{+}$cells (Fig. $2 C$ ) or on the number of $\mathrm{BrdU}^{+}$ cells that expressed the neuronal markers Dcx and/or NeuN. There were no significant differences between control and Rac1 mutant animals in the relative maturation state of neurons labeled with BrdU, indicating that baseline neurogenesis was unaltered in Rac1 mutants.

\section{Rac1 mutants have prolonged memory retention for previously learned spatial information}

Mice were trained in the DMP task (Fig. 3), which is commonly used to assess spatial encoding and place learning in rodents. The 

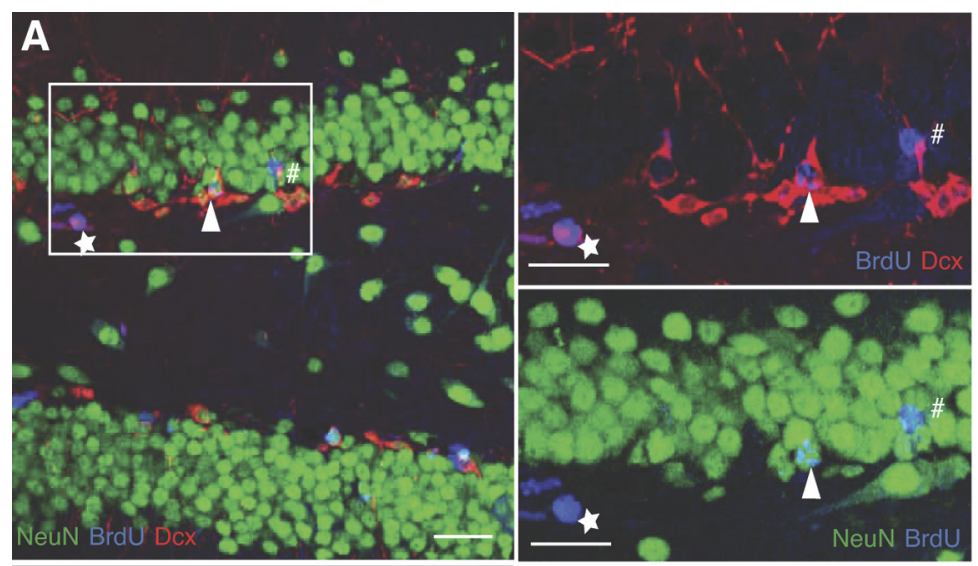

Neuronal subtypes of $\mathrm{BrdU}^{+}$cells: proliferative (x) $\mathrm{Dcx}^{+}$neuroblast intermediate $(\boldsymbol{\Delta}) \mathrm{Dcx} / \mathrm{NeuN}^{+}$neuron mature (\#) $\mathrm{NeuN}^{+}$neuron

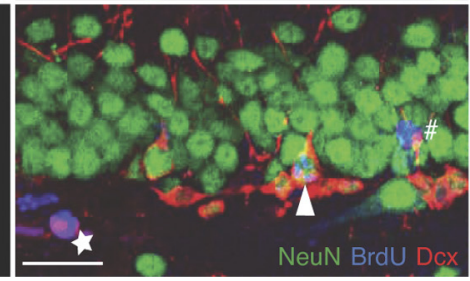

B
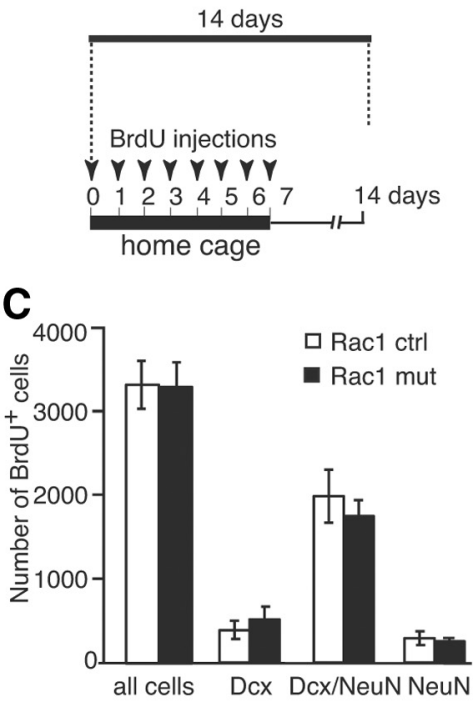

Figure 2. Loss of Rac1 does not affect basal neurogenesis. $A$, Confocal micrograph of BrdU ${ }^{+}$neurons showing BrdU (blue), Dcx (red), and NeuN (green) staining. Neurons were subdivided into still proliferative $D c x{ }^{+}$neuroblasts (star), intermediate $\mathrm{Dcx} / \mathrm{NeuN}^{+}{ }^{+}$neurons (arrowhead), and mature NeuN ${ }^{+}$neurons (\#). Scale bars, $20 \mu \mathrm{m} . \boldsymbol{B}$, Naive mice were injected once per day with BrdU $(50 \mathrm{mg} / \mathrm{kg})$ for $7 \mathrm{~d}$ and neurogenesis was assessed $14 \mathrm{~d}$ after the first BrdU injection. C, No changes in the number of BrdU ${ }^{+}$cells (all cells) or neuron number were detected in naive Rac 1 mutant mice (controls, $n=11 ;$ mutants, $n=10 ;$ ANOVA, $p>0.9$ ).

acquisition of a spatial working memory in the DMP task relies on two major mnemonic components. First, the animals must recognize and remember the specific location of an escape platform using distal spatial cues surrounding the maze, thus the rodents must have the ability to efficiently and rapidly encode representations of their spatial environment. The second learning component in the DMP task is recognizing that the platform position changes each day (Fig. $3 A$ ). Animals must recognize that the old platform position is no longer valid and release this memory while efficiently finding and encoding the new platform location (Morris and Frey, 1997; Xavier et al., 1999; Steele and Morris, 1999).

On a given day, a reduction in the time to find the hidden platform with each successive trial represents the animal's ability to learn the task (Fig. 3B). The reduction in time to find the platform between the first and second trials (savings time) is also considered a measure of the strength of the "working memory" encoded by locating the new platform location in the first trial (Fig. 3C). We have previously shown that loss of Racl in neurons has substantial negative impact on both measures (Fig. 3B,C) (Haditsch et al., 2009), suggesting overall impaired working memory in the Rac1 mutants. We thus assessed whether Rac1 mutant mice showed prolonged memory retention within a training day by assessing the time spent in previous platform areas (platform position of the previous day; Fig. $3 D$ ) and the amount of previous platform areas crossings (Fig. 3E). In both measurements Racl mutants displayed significant higher values within the last four training bins of a day, suggesting that the impairment in the working memory in Racl mutants is due to prolonged memory retention or perseveration of the previously learned platform location. Swim speed (Fig. $3 F$ ) and thigmotaxis (time in outer annulus; data not shown) were not affected in the Rac1 mutant mice.
Loss of neuronal Rac1 has no effect on learning-induced survival of new neurons but impairs learning-evoked increase in proliferation

Associative learning results in the increased survival of young neurons produced in the days just before learning and also stimulates an increase in progenitor cell proliferation following several days of training (Shors et al., 2001; Döbrössy et al., 2003; Anderson et al., 2011). To assess the role of neuronal Rac1 on an experience- or learning-evoked increase in the abundance of newborn neurons, mice were injected with CldU daily for 1 week before the start of DMP training. This labels newly generated neurons, which have a higher survival rate following learning. Mice were also injected with IdU on days 7 and 8 of the DMP task, a time in training when an increase in progenitor proliferation has been previously reported (Döbrössy et al., 2003; Dupret et al., 2007). Animals were killed $24 \mathrm{~h}$ after IdU injection on training day 8 to evaluate proliferation during training, or on day 17 after the start of training, $11 \mathrm{~d}$ after the last IdU injection, to evaluate potential effects on the survival of neurons born during training (Fig. 4A). Stereological estimates of $\mathrm{CldU}^{+}$and $\mathrm{IdU}^{+}$cell abundance were determined by immunofluorescent staining (Fig. $4 B$ ). The abundance of $\mathrm{CldU}^{+}$cells labeled just before training was unaffected by loss of neuronal Racl (Fig. 4C). In contrast, analysis of cells labeled with IdU on day 7 and evaluated on day 8 of training showed a significant reduction in the proliferation in Racl mutant animals during learning (Fig. $4 D$ ). IdU $^{+}$cells present at day 17 were also reduced by approximately the same proportion (Fig. 4E).

A large number of proliferating $\mathrm{IdU}^{+}$cells at day 8 were also labeled with $\mathrm{CldU}^{+}$, indicating that many of the dividing cells were derived from the previously dividing pool of $\mathrm{CldU}^{+}$progenitors. Loss of neuronal Racl reduced the number of $\mathrm{IdU}^{+}$ cells recruited from the previously dividing pool during learning (Fig. $4 F$ ). Double-labeled cells accounted for $76.7 \pm 3.7 \%$ of the 
A
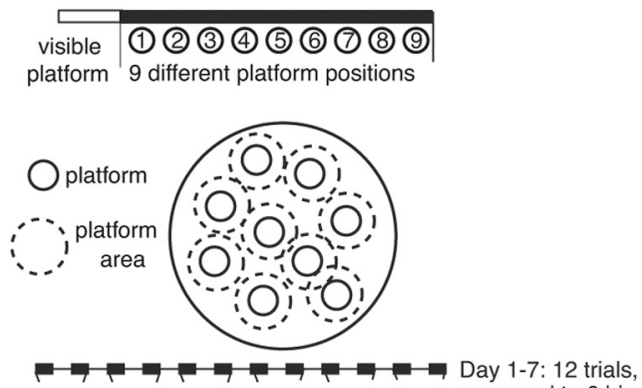

$1,1,1,1,1,1,1,1$ averaged to 6 bins, 5 min ITI Day 8-9: 6 trials, $1 \mathrm{~h}$ ITI

B

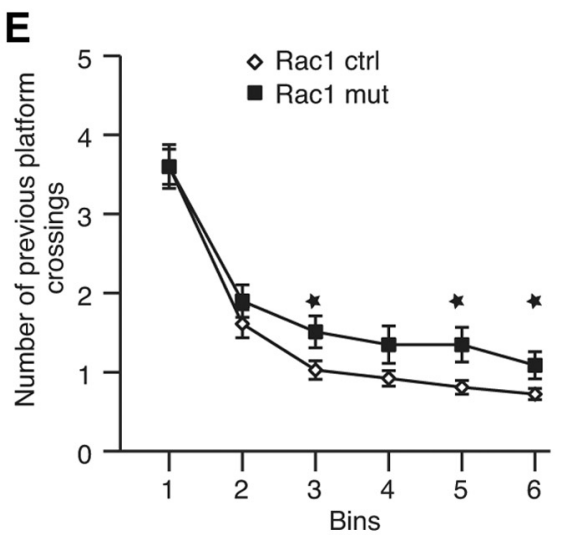

C

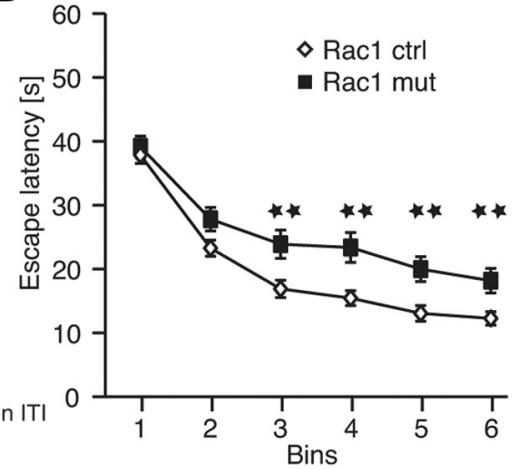

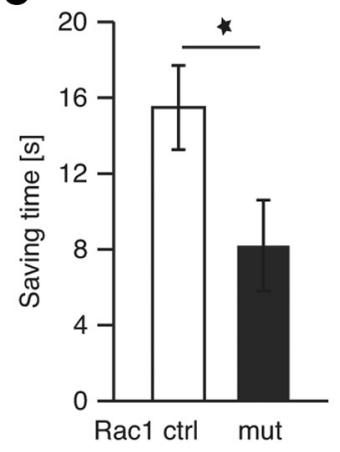

D

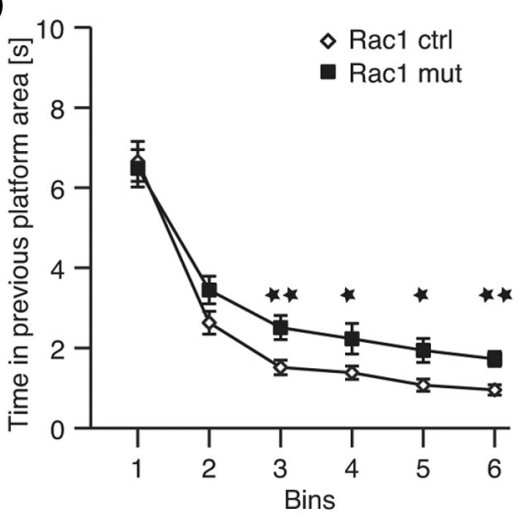

$\mathbf{F}$

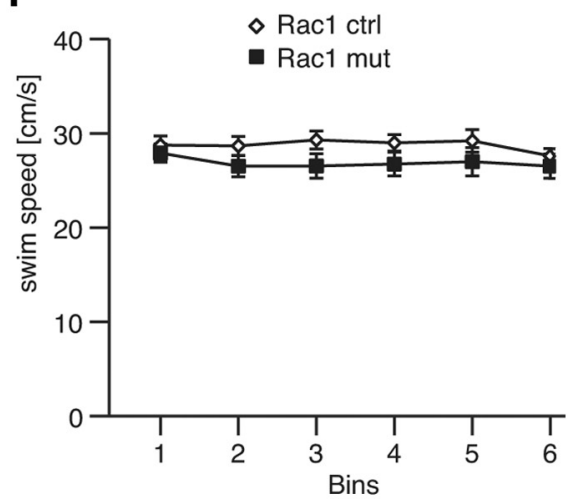

Figure 3. Impaired working memory in Rac1-deficient mice. $\boldsymbol{A}$, Experimental setup of the DMP paradigm. After $1 \mathrm{~d}$ training in the cued version of the Morris water maze, animals were trained for $9 \mathrm{~d}$ in the DMP task, learning 10 different platform locations (one per day). On days $1-7$, the interval between training trials was 5 min; on days 9 and 10 , the interval was increased to $1 \mathrm{~h}$. $\boldsymbol{B}$, Latencies averaged from days 1-9. Rac1-deficient mice (Rac1 mut) displayed impaired working memory (Rac1 controls, $n=18 ;$ Rac1 mutants, $n=19 ;$ three-way repeated-measures AN0VA for overall genotype effect, $F_{(1,35)}=8.03, p<0.01$ and ANOVA with Newman-Keuls post hoc test, $\left.{ }^{* *} p<0.01\right)$. C, Rac1 mutant mice showed a significant decrease in the time saved (reduction in latencies) between the first and second trials of each day, averaged from all days (ANOVA, $F_{(1,35)}=4.84,{ }^{*} p<0.05$ ). $D$, Rac 1 mutants spent significantly more time in the previous platform area (overall genotype effect, two-way repeated-measures ANOVA, $F_{(1,35)}=7.38, p<0.01$, ANOVA with Newman-Keuls post hoc test, ${ }^{*} p<0.05,{ }^{* *} p<0.01$ ). $\boldsymbol{E}$, Rac1 mutants crossed the previous platform area more often (ANOVA, $F_{(1,35)}=4.47, p<0.05$ for genotype effect, post hoc test, ${ }^{*} p<0.05$ ), suggesting increased memory retention of the previously learned platform position. $\boldsymbol{F}$, There were no significant differences in swim speed between Rac1 control and mutant mice (ANOVA, $p>0.8$ ).

$\mathrm{IdU}^{+}$cells in control learners but only $60.0 \pm 7.4 \%$ of the $\mathrm{IdU}^{+}$ cells in Rac1 mutant learners.

\section{AMPA receptor potentiation rescues learning and learning-evoked neurogenesis}

Loss of neuronal Rac1 impairs synaptic plasticity in part by attenuating AMPA receptor clustering evoked by neuronal activity (Tashiro et al., 2000; Tashiro and Yuste, 2004; Wiens et al., 2005). Pharmacological potentiation of AMPA receptor function can partially compensate for defects in excitatory synaptic signaling and small molecule AMPA receptor modulators have been shown to enhance performance in working memory (Lauterborn et al., 2000; Arai and Kessler, 2007). To determine whether such an approach would rescue learning and/or learning-evoked neurogenesis in the DMP task, training was initiated for Racl mutants and control mice. The expected deficits were noted in Rac1 mutant animals for the first $3 \mathrm{~d}$ of training (three-way repeatedmeasures ANOVA, $\left.F_{(1,19)}=10.19 ; p<0.01\right)$. On day 4 , and for each successive day, mice were injected with the CX546, an allosteric AMPA receptor modulator, $30 \mathrm{~min}$ before testing (Fig. $5 A$ ). Mice were also injected with BrdU on days 7 and 8 of training. Accentuating AMPA receptor signaling during learning reversed the learning deficits in Rac1 mutant animals (Fig. 5B). Quantitative assessment of BrdU-positive cells revealed that Cx546 elevated neurogenesis to the same levels in both control and Racl mutant animals (Fig. 5C).
Previous studies have shown that treatment with Cx546 increases BDNF expression (Lauterborn et al., 2000; Arai and Kessler, 2007) and BDNF regulates both proliferation and the survival of neuronal precursors (Ma et al., 2009b; Choi et al., 2009). We therefore examined the levels of BDNF expression in Racl control and mutant learners after drug treatment. Assessment of BDNF staining intensity in neurons of control animals and Rac1 mutant animals confirmed that loss of Rac1 prevented the increase in BDNF protein abundance that is normally induced during learning. We quantified BDNF expression in reporter-positive cells of the granular cell layer of the DG and the pyramidal cell layer of the CA1 (Fig. 5D). Rac1 mutant learners had statistically significant reductions in the fraction of cells that stained positive for BDNF in both regions of the hippocampus (Fig. 5E). Cx546 induced a significant increase in BDNF staining in both control and mutant animals, resulting in no significant difference between genotypes (Fig. 5E). Consistent with BDNF's known ability to increase dendritic spine numbers (Haditsch et al., 2009), Cx546 treatment also resulted in significant increases in PSD$95^{+}$spines in control and mutant mice and eliminated the differences in PSD-95 between control and Racl mutants (Fig. 5F).

Loss of neuronal Rac1 alters Gadd45b, BDNF, and TrkB expression

Activity-induced expression of neuronal Gadd45b has been implicated in regulating expression of Fgfl $\beta$ and BDNF genes (Ma 
A

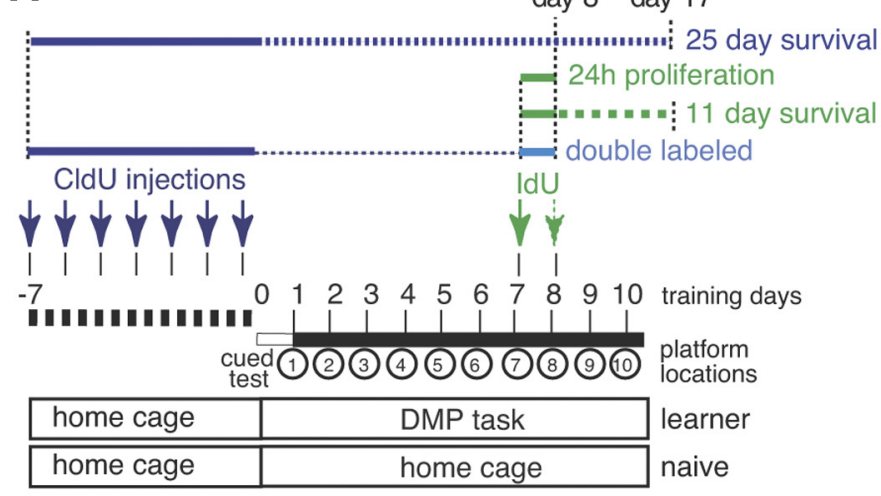

C

Survival of cells labeled before learning

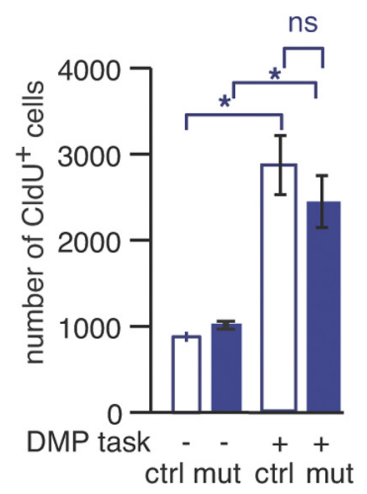

D Proliferation
during learning

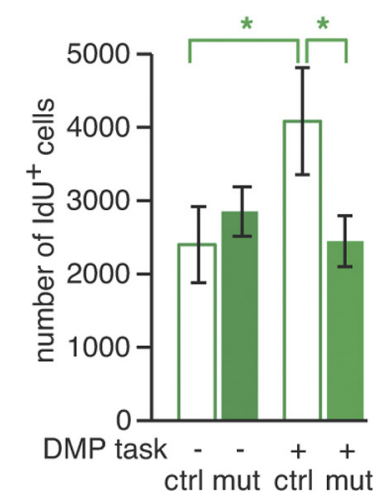

B
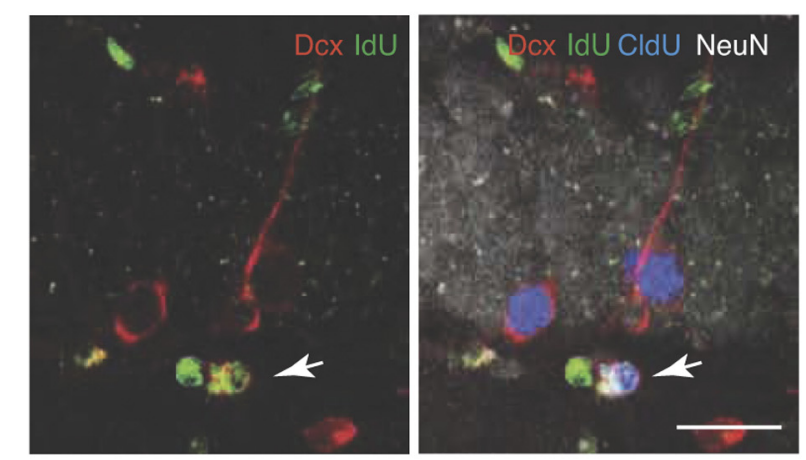

E

Survival of cells
labeled during learnin

$\mathbf{F}$

Double labeled proliferative cells

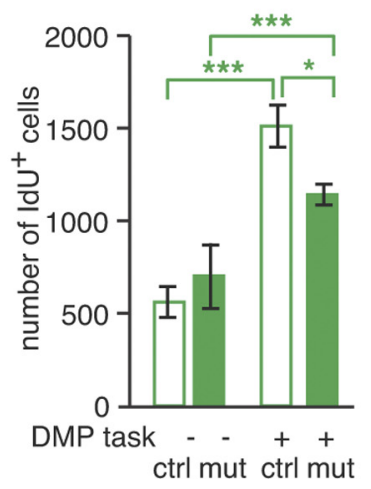

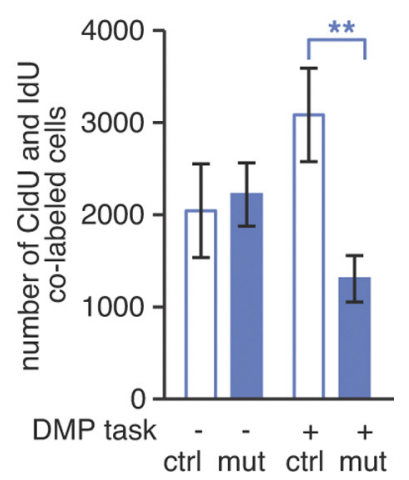

Figure 4. Loss of Rac1 decreases neurogenesis during learning. A, Mice received daily CldU injections ( $50 \mathrm{mg} / \mathrm{kg}$ ) for $7 \mathrm{~d}$ before the onset of DMP training. To assess survival of cells born just before learning, animals were injected with CldU daily for 1 week before training and killed on day 17 after the start of training. To assess proliferation during training, mice were injected with IdU (100 $\mathrm{mg} / \mathrm{kg}$ ) on training day 7 and killed on day 8 . For the analysis of survival of newly generated neurons produced during learning, another set of mice was injected with ldU ( $50 \mathrm{mg} / \mathrm{kg}$ ) on days 7 and 8 and killed on day 17. Naive mice were injected with the same CIdU and IdU injection protocol as learner groups, but remained in their home cages the entire time. $\boldsymbol{B}$, Picture of colocalization of IdU (green) with Dcx (red) and CIdU (blue) in the granular cell layer of the DG. Arrow indicates a triple-labeled CldU ${ }^{+}$IdU ${ }^{+}$Dcx ${ }^{+}$neuron. Scale bar, $20 \mu m$. C, Comparison of CIdU ${ }^{+}$cell numbers in naive DMP-trained mice on day 17. Learning significantly increased the number of CldU ${ }^{+}$cells when compared with naive groups (learning effect); there was no significant difference between control and Rac1 mutant mice (control learners, $n=5$; mutant learners, $n=5$; control naive, $n=4$; mutant naive, $n=4$; ANOVA with post hoc test, ${ }^{*} p<0.05$ ). Ns, not significant; ${ }^{*} p<0.05$. $D$, Mitotic index on day 8 during of learning. Learning significantly increased proliferation in control learners compared with control naive animals (learning effect, control learners, $n=5$; control naive, $n=6$; ANOVA with post hoc test, ${ }^{*} p<0.05$ ). However, Rac1 mutant learners had significantly fewer IdU ${ }^{+}$cells when compared with control learners (control learners, $n=5$; mutant learners, $n=8$; ANOVA with post hoc test, ${ }^{*} p<0.05$ ). $\boldsymbol{E}$, Survival of IdU ${ }^{+}$cells produced during learning. Control learners retained significantly more IdU ${ }^{+}$cells when compared with control naive animals on day 17 (learning effect; control learners, $n=5$; control naive, $n=4$; ANOVA with post hoc test, ${ }^{* * *} p<0.001$ ). During learning fewer ldU ${ }^{+}$cells were generated in Rac1 mutant learners $(n=5)$ when compared with control learners $\left(n=5 ;\right.$ ANOVA, $\left.F_{(1,8)}=8.55 ; p<0.05\right)$ resulting in an overall decrease in IdU ${ }^{+}$cell numbers. ${ }^{*} p<0.05,{ }^{* *} p<0.001 . F$, Number of $C l d U{ }^{+}$and $\mathrm{IdU}^{+}$colabeled cells on day 8. During training significantly fewer of the CldU ${ }^{+}$cells incorporated IdU in the Rac 1 mutant mice (control learners, $n=5 ;$ mutant learners, $n=7 ;$ ANOVA, $F_{(1,9)}=11.8$; $\left.{ }^{* *} p<0.01\right)$.

et al., 2009a,b) and loss of Gadd45b reduces neural progenitor proliferation in the hippocampus, in part through decreased BDNF expression. To determine the influence of neuronal Racl in this pathway, hippocampal formations were collected from animals after training in the DMP task for $7 \mathrm{~d}$ and dissociated cells were fractionated into populations enriched for NPCs or differentiated neurons (Fig. 6A). qRT-PCR showed a learningevoked increase in Gadd45b in the neuronal fraction of control animals that was absent in Racl mutant animals (Fig. 6B). Similarly, learning evoked an increase in BDNF and TrkB transcripts in progenitor cells (Fig. 6C) that was significantly reduced in Rac1 mutant animals. Reduced abundance of Gadd45b in the mature $\mathrm{NeuN}^{+}$neurons of Rac1 mutant DG was evaluated by immunohistochemistry (Fig. 6D) and quantification of the percentage of pixels positive for Gadd45b confirmed a 17\% reduction in Rac1 mutant learners versus Racl control learners (Fig. 6E; control learners $=54.3 \pm 3.4 \%$, mutant learners $=36.9 \pm 2.9 \%$ ). Gadd45b has been implicated in DNA demethylation within the regulatory region IX of the BDNF promoter (Ma et al., 2009a). Bisulfite sequencing of $7 \mathrm{CpG}$ sites within region IX was not able to detect changes in the frequency of DNA methylation in Rac1 mutant relative to control learners (Fig. $6 F$ ), suggesting that reduced Gadd45b in the Rac1 mutant learners had no effect on BDNF promoter methylation.

To further assess the potential role of BDNF signaling in learning-evoked NPC proliferation, TrkB receptor was evaluated for the presence of activating phosphorylation on tyrosine 816 (Y816) in $\mathrm{PSA}-\mathrm{NCAM}^{+}$precursors and $\mathrm{NeuN}^{+}$ mature neurons in the DG by Y816-specific immunostaining (Fig. 6G). Learning evoked an increase in phosphorylated TrkB (pTrkB) staining in PSA-NCAM ${ }^{+}$NPCs that was significantly reduced in Rac1 mutants (Fig. $6 H$ ). p TrkB staining was also significantly reduced in $\mathrm{NeuN}^{+}$mature neurons (Fig. 6I). In combination, these data suggest that neuronal Rac1 signaling is required for an increase in hippocampal Gadd45b/ BDNF signaling during learning. 
A

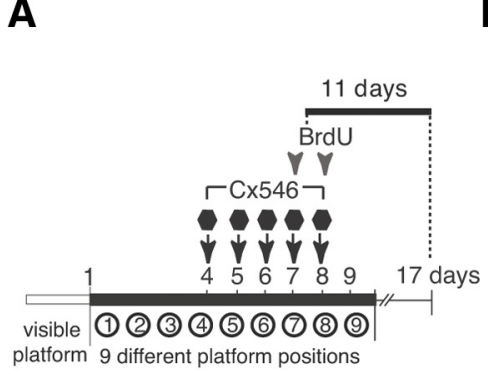

B

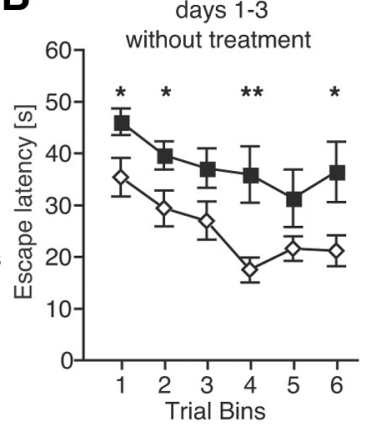

days $4-8$ with Cx546 treatment
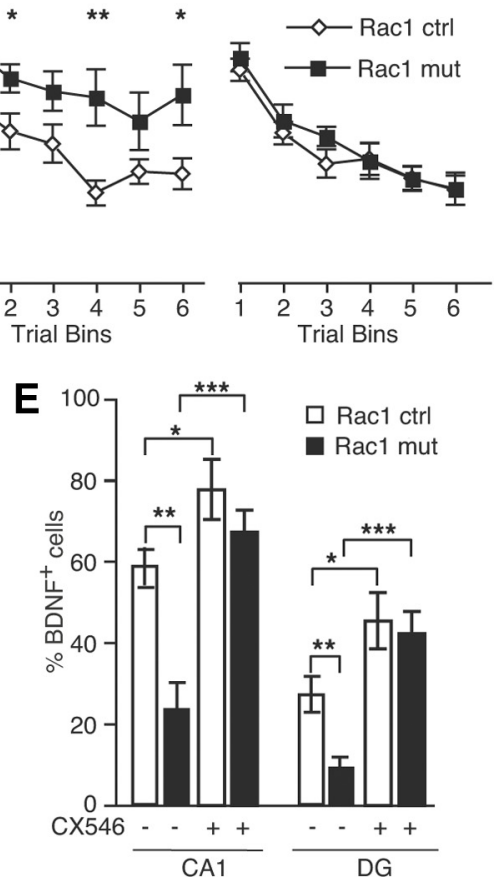

C

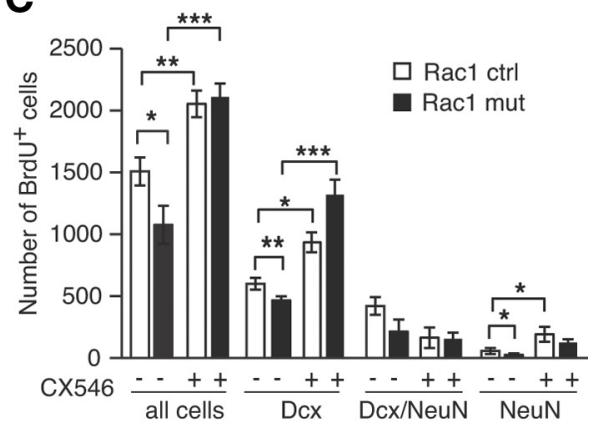

$\mathbf{F}$

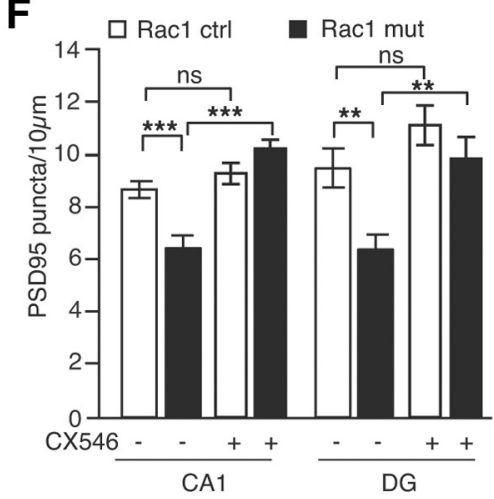

Figure 5. Increasing AMPA receptor potentiation during learning rescued behavioral and neurogenic deficits in Rac1 mutant mice. $\boldsymbol{A}$, Rac1 control and mutant mice were trained in the DMP task as previously described in Figure 3, but received daily intraperitoneal injections with Cx546 or saline $1 \mathrm{~h}$ before the training on days $4-8$. New neurons produced during learning were labeled by two BrdU (50 mg/kg) injections on training days 8 and 9. B, Performance of Rac1 control and mutant mice before and during drug treatment. As previously reported in Figure 3 , loss of Rac 1 in mature neurons impairs working memory (days $1-3$ without drug treatment; Rac1 controls, $n=12$; Rac1 mutants, $n=8$; two-way repeated-measures AN0VA with $p$ ost hoc test, ${ }^{*} p<0.05,{ }^{* *} p<0.01$ ). Cx546 treatment on days $4-8$ rescued the working memory deficits in Rac1 mutants (latencies of 6 sessions per day averaged across days $4-9$ ). C, CX546 treatment reversed the deficits in Rac1 mutants. Quantification of the number of BrdU ${ }^{+}$cells $11 \mathrm{~d}$ after the first BrdU injection revealed that Rac 1 mutants treated with saline $(n=7) \mathrm{generated}$ statistically significant fewer BrdU ${ }^{+}$cells (all cells) and $\mathrm{Dcx}{ }^{+}$neurons during learning when compared with saline-treated controls ( $n=7$, AN0VA with post hoc test ${ }^{*} p<0.05$, ${ }^{* *} p<0.01$ ). However, Cx546 treatment groups had significantly more BrdU ${ }^{+}$cells and Dcx ${ }^{+}$neuroblasts and NeuN ${ }^{+}$cells when compared with saline-treated groups (for all groups, $n>5 ;$ treatment effect; ANOVA with post hoc test, ${ }^{*} p<0.05$, ${ }^{* *} p<0.01,{ }^{* * *} p<0.001$; no genotype differences in (x546-treated groups, $p>0.4$ ). D, Double staining of pyramidal neurons of the CA1 for EGFP and BDNF in control (left) and mutant animals (right). About half of the pyramidal cells in the CA1 coexpressed BDNF in control mice. Rac1 mutants showed lower BDNF expression in the same area. Scale bars: $20 \mu \mathrm{m}$. $\boldsymbol{E}$, Quantification of BDNF expression in the pyramidal layer of the CA1 and the granular cell layer of the DG. Rac1 mutants treated with saline displayed a significant drop in BDNF expression in EGFP ${ }^{+}$reporter cells in both regions of the brain when compared with control mice (controls, $n=3$; mutants, $n=6$; ANOVA, in all cases, $F_{(1,7)}>10.0,{ }^{*} p<0.05$, ${ }^{* *} p<0.01$ ). Cx546 treatment significantly increased BDNF expression in both regions to similar levels in control and mutant mice (no genotype effect in C $x 546$-treated groups; $n=4-10$ animals per group; treatment effect; ANOVA with post hoc test, ${ }^{*} p<$ $\left.0.05,{ }^{* *} p<0.01,{ }^{* * *} p<0.001\right) . F$, Quantification of PSD-95 ${ }^{+}$densities in mice trained in the DMP task with Cx546 or saline treatment. Significant reduction in PSD-95 ${ }^{+}$spines in Rac1 mutants when compared with controls (saline-treated groups, $n=3$; ANOVA, $C A 1, F_{(1,4)}=206.3, p<0.001 ; D G, F_{(1,4)}=21.11, p<0.01$ ). Treatment with the $C \times 546$ during learning significantly increased spine density in both groups and rescued the deficits in the mutant mice $(n=3$ for both groups; ANOVA, CA1, $p>0.14 ; D G, p>0.34)$. Ns, not significant; ${ }^{* *} p<0.01,{ }^{* * *} p<0.001$.

\section{Running reverses hippocampal neurogenesis and cognitive deficits in Racl mutant animals}

Previous studies have demonstrated that running can rescue deficits in working memory (Corsini et al., 2009). To determine whether loss of neuronal Racl would impact running-induced neurogenesis and/or a running-induced rescue of learning and memory, running wheels were provided to Racl control and mutant mice for 2 weeks before training in the DMP task ("runnerlearners"). These animals were compared with groups of mice without access to a running wheel ("learners"; Fig. 7A). All mice received daily CldU injection for $7 \mathrm{~d}$ in their home cage before DMP training. Animals were also given IdU on days 7 and 8 of the DMP task to label neurons born during learning and brains analyzed for the abundance and fate of CldU- and IdUlabeled cells on day 17 (Fig. 7A). As expected, running significantly increased the number of $\mathrm{CldU}^{+}$cells produced before the DMP task in Racl control animals. Racl mutant animals also displayed a running-induced increase in $\mathrm{CldU}^{+}$cells that was not significantly different from the increase seen in controls (Fig. 7B), indicating that loss of neuronal Racl had no significant influence on mechanisms that underlie exerciseinduced neurogenesis.

Running before learning also stimulated higher levels of proliferation during learning and the increase in Racl mutant animals was sufficient to attenuate the differences between Rac1 mutant and control animals. Proliferative activity during learning in Rac1 mutant animals was not significantly different from controls within the runner-learner group (Fig. 7C).

Running before learning also normalized performance in the DMP task resulting in no significant differences in escape latency (Fig. 7D), perseverative behavior, or other measures previously shown in Figure 3 (data not shown). An analysis of correlation between NPC proliferation during learning and behavior also showed a significant correlation across all genotypes and treatment groups tested. Memory retention or perseveration (time spent in previous platform area in training bins 2-4) showed a significant negative correlation to proliferative activity during learning (Fig. 7E) and an aggregate performance index (a composite score of escape latency and reduced perseveration) showed 
A
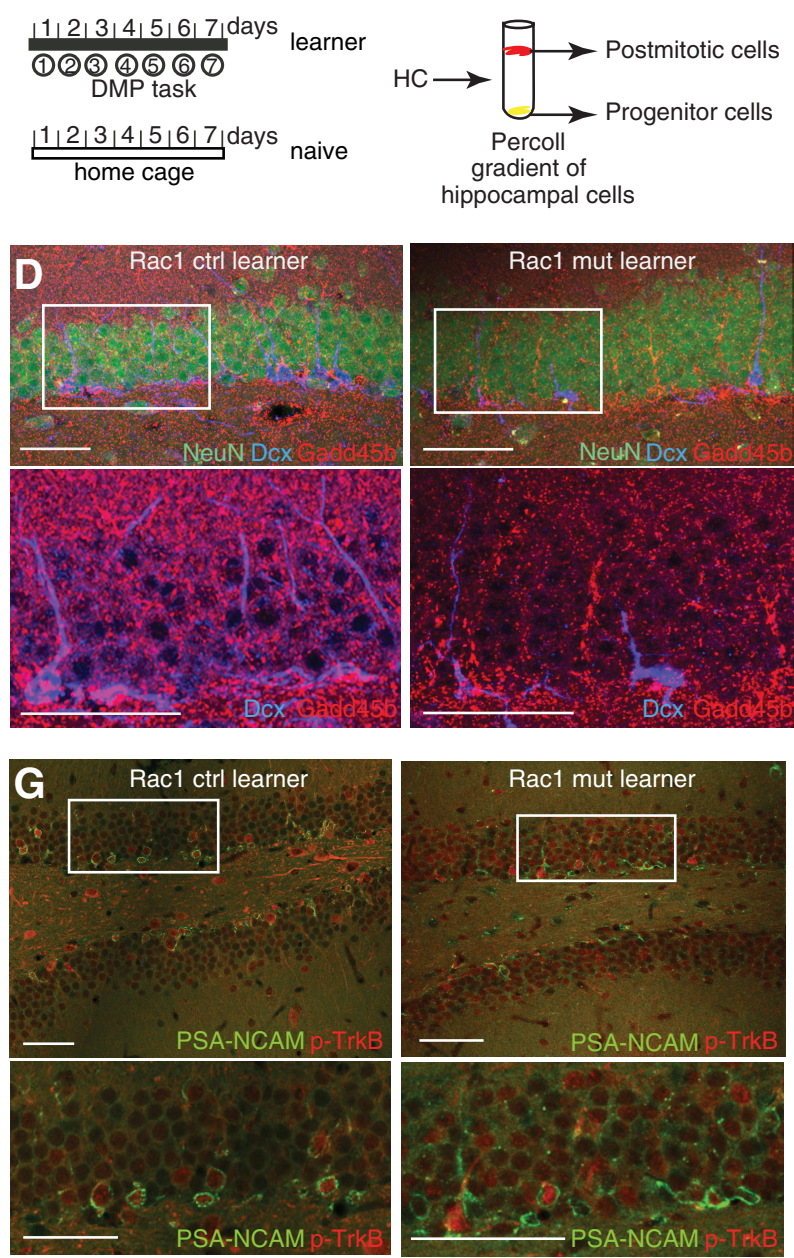

B

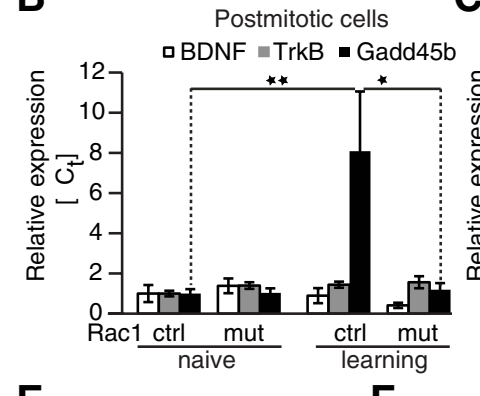

E

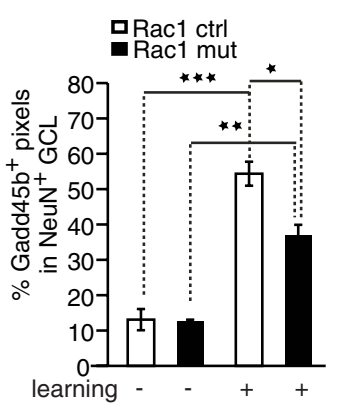

$\mathbf{F}$

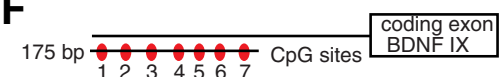

H
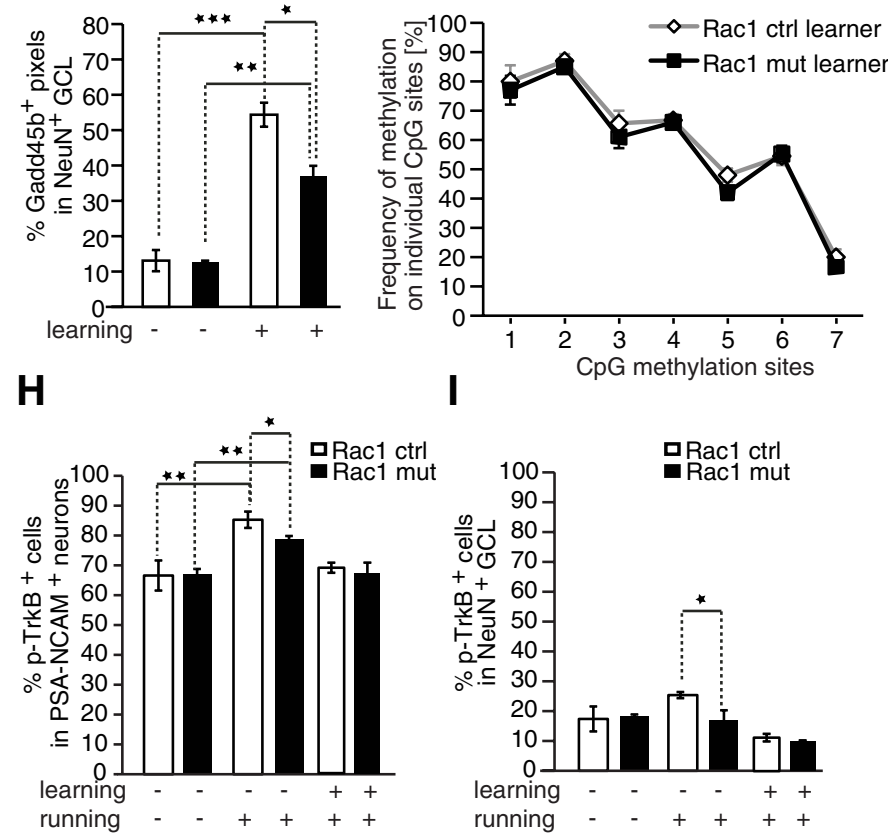

Progenitor cells - BDNF $=$ TrkB - Gadd45b
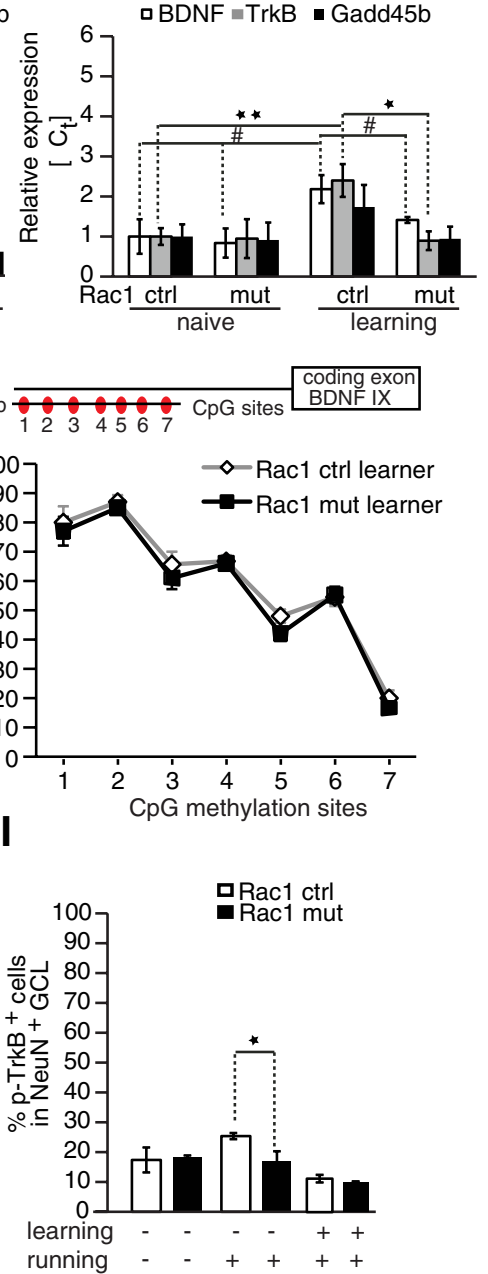

Figure 6. L Lss of neuronal Rac1 alters Gadd45b, BDNF, and TrkB expression. A, Isolation of NPCs and mature neurons from the hippocampus of adult mice. Microdissected DGs were collected form naive mice and mice trained in the DMP task and rapidly dissociated into live cell suspensions that were enriched by Percoll density centrifugation for immature neural progenitors or mature neurons and glia. $B$, C, Relative BDNF, Gadd45b, and TrkB mRNA levels in enriched cell fractions of DG. Gadd45b expression was significantly upregulated during $7 \mathrm{~d}$ of learning in the mature neuron fraction (B) of Rac1 control learners ( $n>5$ for all groups of mice; ANOVA with post hoc test, ${ }^{* *} p<0.01,{ }^{*} p<0.05$ ). In the NPC enriched fraction (C), TrkB and BDNF expression was increased in Rac1 control (ctrl) learners, but not in Rac1 mutant learners (control naive, $n=8$, control learners, $n=5$; ANOVA with post hoc test, ${ }^{\#} p<0.1$ trend, ${ }^{* *} p<0.01$; control learners vs mutant learners, $n=4$; ANOVA with post hoc test, ${ }^{\#} p<0.1$ trend, $\left.{ }^{*} p<0.05\right)$. $\boldsymbol{D}$, Gadd45b expression in $\mathrm{NeuN}^{+}$mature dentate granule cells of the adult mouse hippocampus. Shown are sample confocal images of Gadd45b (red), NeuN (green), and Dcx (blue) immunostaining in Rac1 control (left) and Rac1 mutant mice (right) after $7 \mathrm{~d}$ of training in the DMP task. Scale bars, $50 \mu \mathrm{m}$. E, Quantification of the percentage of Gadd45b-positive pixels within the NeuN ${ }^{+}$cells in the granular cell layer. Learning significantly increased immunoreactivity for Gadd45b in mature neurons in control learner (control naive vs learners, ANOVA with post hoc test, ${ }^{* * *} p<0.001$ ), and to a lesser extent in Rac1 mutant learners (mutant naive vs mutant learners, ANOVA with post hoc test, ${ }^{* *} p<0.01$ ). Comparison between learners revealed significant differences between genotypes (control learner vs mutant learner, ANOVA with post hoc test, ${ }^{*} p<0.05$ ). $\boldsymbol{F}$, Bisulfite sequencing analysis of the methylation status within the BDNF IX regulatory promoter region as described previously (Ma et al., 2009a). No changes in DNA methylation frequency in seven individual C $p$ G sites of BDNF IX were observed in Rac1 control and mutant mice after $7 \mathrm{~d}$ of training in the DMP task. G, Immunostaining of phosphorylated TrkB (p-TrkB, red) and the neuronal precursor marker PSA-NCAM (green) in the DG of Rac1 control learner (left) and Rac1 mutant learner (right). Scale bars: $50 \mu \mathrm{m}$. $\boldsymbol{H}, \boldsymbol{I}$, Percentage of p-TrkB ${ }^{+}$cells among all PSA-NCAM ${ }^{+}$NPCs $(\boldsymbol{H})$ and the $\mathrm{NeuN}^{+}$mature neurons $(\boldsymbol{I})$ within the DG of naive, DMP-trained mice (learners) and runner-learners (Fig. $\left.7 A\right)$. Learning significantly increased the number of $p$-TrkB ${ }^{+} \mathrm{NPCs}(\boldsymbol{H})$ in Rac1 control and mutant learners (naive vs learners for both genotypes, ANOVA with post hoc test, ${ }^{* *} p<0.01, n=3$ for all groups). Comparison between learners revealed significantly lower $\mathrm{p}$-TrkB ${ }^{+}$cells numbers in Rac1 mutant learners in NPCS $(\boldsymbol{H})$ and in NeuN ${ }^{+}$mature neurons $(\boldsymbol{I})$ (control learners vs mutant learners, ANOVA with post hoc test, ${ }^{*} p<0.05, n=3$ for all groups). Running before learning had no significant effect on $\mathrm{p}$-TrkB levels and no changes were observed between Rac1 control and mutant mice within the runner-learner groups (control runner-learners vs mutant runner-learners, $n=3$ for both groups; ANOVA, $p>0.2$ ).

a positive correlation with the abundance of $\mathrm{Dcx}^{+}$cells produced during learning (Fig. $7 F$ ).

\section{Loss of Rac1 in postmitotic neurons of the hippocampus affects NPC cycle regulation}

Kowalczyk et al. (2004) have suggested that the proliferation of NPCs in the DG is controlled by cyclin D2. To assess whether changes in proliferation in Racl mutant learners are due to changes in the expression of cell cycle regulators, enriched NPC populations were isolated from the hippocampi of naive animals, learners, and runner-learners that were trained for $7 \mathrm{~d}$ in the DMP task and killed on day 8. qRT-PCR revealed no significant differences in transcript abundance for cyclin D1 and D2 or cyclin-dependent kinases (Cdk) 2, 4, and 6 between genotypes or between learners versus naive animals. However, Rac1 mutant learners showed significantly higher levels of Cdk inhibitor $1 \mathrm{~B}$ (p27 Kip1) mRNA compared with control learners (Fig. 8A). Running before learning normalized p27 Kip1 in Rac1 mutant 
A

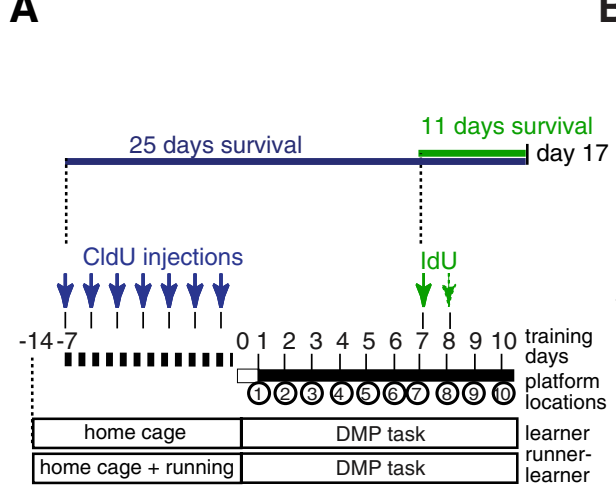

B

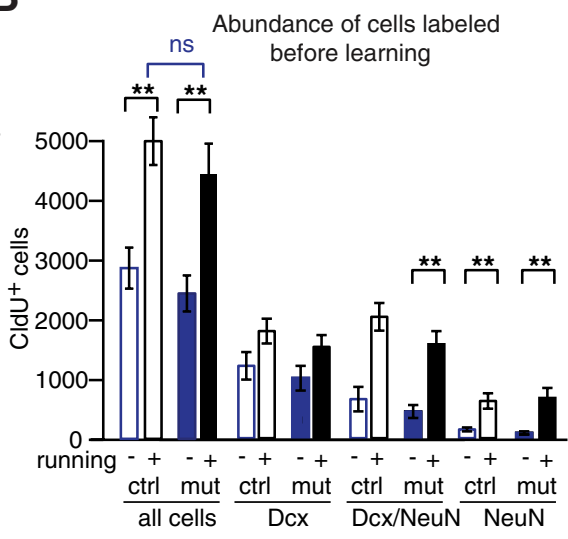

C

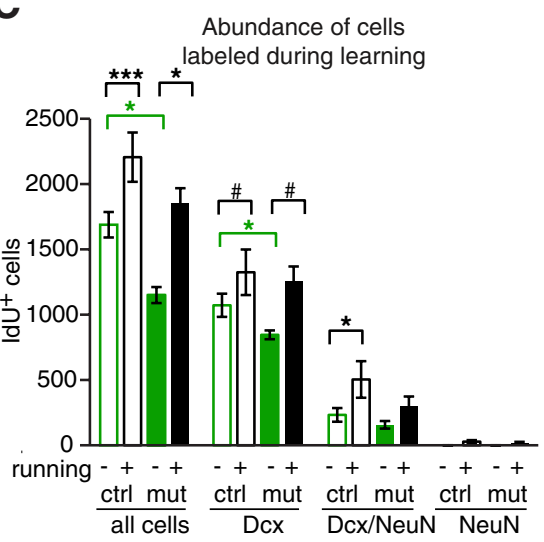

$\mathbf{F}$

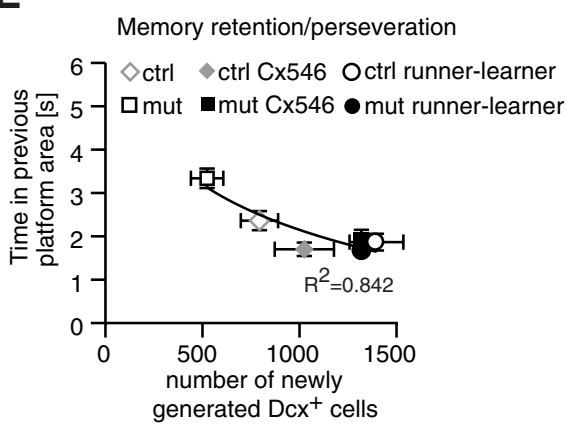

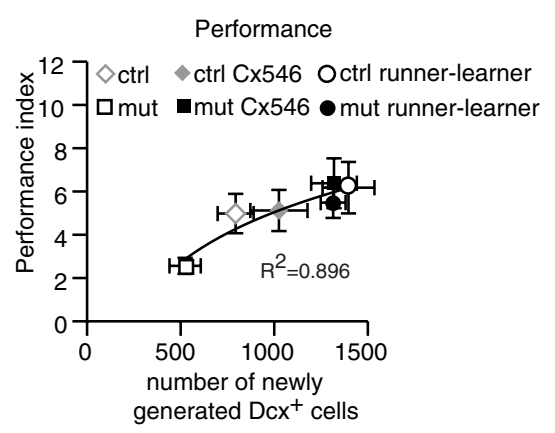

Figure 7. Voluntary running before learning reversed neurogenic, behavioral, and transcriptional deficits in Rac1 mutant mice. A, Animals were either allowed to run for 2 weeks (runnerlearners) or stayed in their home cages (learners) before training in the DMP task and received daily CldU injections $(50 \mathrm{mg} / \mathrm{kg})$ for $7 \mathrm{~d}$ before the onset of learning. During training, all groups of mice were injected with IdU on days 7 and 8 , and neurogenesis was assessed on day 17. B, Number of CldU ${ }^{+}$cells produced before learning was not changed in Rac1 mutant mice (no genotype effect within learners and runner-learners, control learners, $n=5$; mutant learners, $n=5$; control runner-learners, $n=8$; mutant runner-learners, $n=6$; ANOVA, $p>0.18$ ). Running significantly increased the number of newly generated $\mathrm{Dcx} / \mathrm{NeuN}{ }^{+}$intermediate-state neurons and NeuN ${ }^{+}$mature neurons in both Rac1 mutant and control mice to the same extent (running effect; ANOVA with post hoc test, $p<0.01)$. Ns, not significant, ${ }^{* *} p<0.01$. C, During learning fewer IdU ${ }^{+}$cells and Dcx ${ }^{+}$neuroblasts were generated in mutant learners $(n=5)$ when compared with control learners $(n=5$; ANOVA with post hoc test, $p<0.05)$. Running before learning restored neurogenesis in Rac1 mutant runners-learners to levels that were not significantly different from control runner-learners (no genotype effect; mutant runner-learners, $n=6$; control runner-learners, $n=8$; ANOVA $p>0.07$ ). ${ }^{*} p<0.05,{ }^{* * *} p<0.001$. $\boldsymbol{D}$, Running before learning rescued the working memory deficits in Rac1 mutant mice (control runner-learners, $n=19$; mutant runner-learners, $n=15$; two-way ANOVA, $p>0.5$ ). $E$, Correlation between increased memory retention of previously learned platform position and the number of newly generated $D c{ }^{+}$neurons. Rac1 mutant mice spent significantly more time in the previous platform area (measured during the last 4 training trials each day), which results in lower performance in the DMP task. This increased perseverative use of previously learned information correlates with low numbers of newly generated $\mathrm{Dcx}{ }^{+}$neurons. Running and CX546 treatment significantly decreased the time spent in the previous platform area in Rac1 mutant mice (logarithmic best-fit with $R^{2}$ value $\left.>0.8\right) . F$, Correlation between performance index and the number of newly generated $D c x^{+}$neurons in learners, runners-learners, and learners treated with $C X 546$. Performance index was calculated as a composite score of escape latency and time spent in previous platform area. Rac1 mutant animals show the expected relationship of low Dcx ${ }^{+}$cell numbers and reduced performance. Running and CX546 treatment did not further attenuate the performance in control mice, but significantly improved Rac1 mutant mice resulting in a shift toward higher $D c x^{+}$numbers and increased performance (correlation between performance index and IdU/Dcx ${ }^{+}$cell numbers; logarithmic best-fit with $R^{2}$ value $>0.8$ ).

learners. Immunostaining for p27 Kip1 protein in the DG confirmed colocalization of p27 Kip1 with Dcx ${ }^{+}$NPCs (Fig. 8B), suggesting that loss of Racl in mature neurons may result in increased cell cycle exit of NPCs during learning.

To determine whether Rac1 mutant learners show alterations in cell cycle exit, dividing cells were labeled during learning with a single IdU pulse on day 7 and assessed the fraction of cell leaving the mitotic cycle by costaining of IdU with the proliferation marker Ki67 (Fig. 8C). Quantification of the $\mathrm{IdU}^{+} / \mathrm{Ki}^{-} 7^{-}$cells among all $\mathrm{IdU}^{+}$cells revealed a significantly larger "quit" fraction in Rac1 mutant learners compared with control learners.

TGF- $\beta 1$ is known to promote cell cycle arrest by suppressing expression and function CDKs and enhancing expression of CDK inhibitors, such as p15INK4B, p21CIP1 and p27 Kip1 (Ammanamanchi et al., 2004; Kubiczkova et al., 2012). We found that control animals trained in the DMP task had significantly lower levels of TGF- $\beta 1$ mRNA expression in the DG when compared with naive littermates. Loss of neuronal Racl prevented the learning-induced downregulation of TGF- $\beta 1$ (Fig. $8 D$ ). These results in combination suggest that loss of Rac1 in mature neurons result in increased cell-cycle exit of NPCs in part by decreasing the expression of activity-dependent growth factors such as BDNF and by increasing TGF- $\beta 1$.

\section{Discussion}

The signaling and cellular adaptations that occur within the hippocampus change over the course of a traditional learning paradigm. For example, Döbrössy et al. (2003) have shown that during the initial phase of learning in the Morris water maze reference memory task, neurons produced 1 week before training show evidence of increased survival. Anderson et al. (2011) also show that associative learning (trace eye blink conditioning) increases the survival of 1-2-week-old cells, but not of very young (4-d-old) or older (3- to 4-week-old) cells and that the survival of the young neurons depends on NMDA-receptor activity during learning. Blocking NMDA receptor function each day after training sessions neither impaired associative learning nor altered cell survival, suggesting that NMDA receptor activity is essential dur- 
A

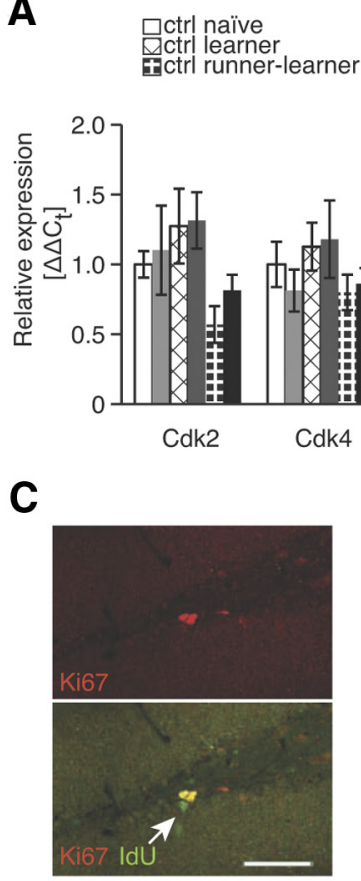

$\square$ mut naïve mut leaner

mut runner-learner

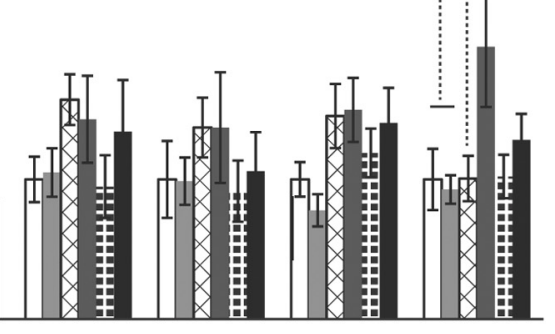

Cdk6 cyclin D1 cyclin D2
B

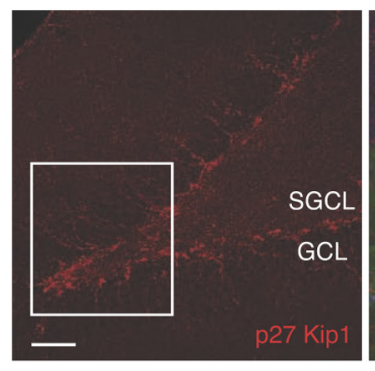

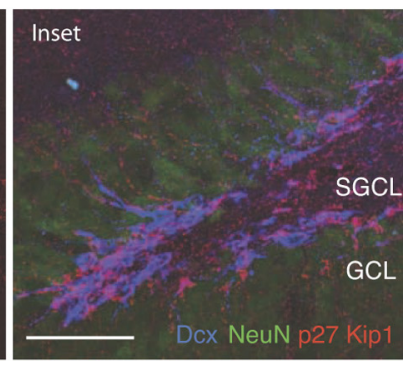

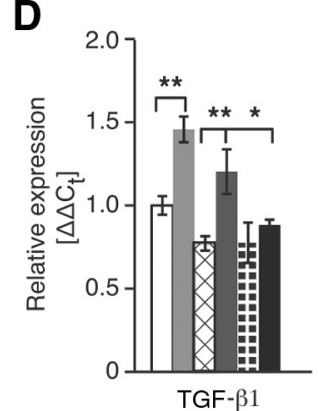

Figure 8. Loss of Rac1 in postmitotic neurons of the hippocampus affects NPC cycle regulation. $A$, Comparison of relative mRNA expression levels of cell cycle regulators in the DG. The experimental setup was the same as in Figure $7 A$, except that learner and runner-learner groups were killed on day 8 (after 1 week of learning). Microdissected DG tissue from naive, learners, and runner-learners was subjected to qRT-PCR analysis. Values were normalized to those of $\beta$-actin for each sample and then normalized to the control naive group. No changes in $m R N A$ expression for $C d k 2,4$, and 6 and cyclin D1 and D2 were observed when comparing Rac1 control groups with Rac1 mutant groups. However, Rac1 mutant learners had significantly higher levels of Cdk inhibitor 1B (p27 Kip1) compared with all the other groups (for all groups, $n=5$, ANOVA with post hoc test, ${ }^{*} p<0.05$ ). $\boldsymbol{B}$, Immunostaining of $p 27$ Kip1 in the DG. p27 Kip 1 protein expression (red) was predominantly found in the subgranular cell layer (SGCL) and to a lesser extent in the granular cell layer (GCL) of the DG. Expression colocalized with Dcx ${ }^{+}$cells (blue) in the SGCL and with NeuN ${ }^{+}$cells in the GCL. Scale bars, $50 \mu \mathrm{m}$. C, Increased cell cycle exit in Rac1 mutant mice during learning. Double immunofluorescence for Ki67 (red) and IdU (green) after $24 \mathrm{~h}$ survival to a single IdU pulse at training day 7 . Cells labeled only with IdU were more abundant in Rac1 mutant learners. Scale bar, $40 \mu \mathrm{m}$. Quantification of the fraction of cells leaving the mitotic cycle (quit fraction: percentage of the number of IdU ${ }^{+}$, Ki67 ${ }^{-}$cells among the total of IdU ${ }^{+}$cells). In Rac1 mutant learners, the number of cells that leave the cell cycle was significantly increased compared with control learners $\left(n=3-4\right.$, ANOVA, $F_{(1,5)}$ $\left.=6.7,{ }^{*} p<0.05\right)$. D, Relative abundance of TGF- $\beta 1 \mathrm{mRNA}$ in the DG. Rac1 mutant mice had significantly higher levels of TGF- $\beta 1$ expression as measured by qRT-PCR compared with their control groups (control naive vs mutant naive and control learners vs mutant learners, $n=3-5$, ANOVA with post hoc test, ${ }^{* *} p<0.01$ ).

ing the actual learning event (Curlik and Shors, 2011; Waddell et al., 2011).

Since Rac1 activation occurs downstream of the NMDA receptor activation in neurons and NMDA receptor activation is required for experience-related increase in young postmitotic neuron survival, we anticipated that loss of Racl would preferentially influence the survival of 1- to 2-week-old cells as shown by Anderson et al. (2011), but this is clearly not the case. Both Racl control and mutant animals showed normal experience-dependent increases in the survival of neurons that were produced in the week just preceding training (Fig. 4B). In contrast, we found that that loss of Rac1 in CaMKII $\alpha$-expressing mature projection neurons specifically prevented the learningevoked increase in proliferation that occurs later in the training paradigm (Fig. 4C,D) (Döbrössy et al., 2003).

Within the mature neurons of the DG, loss of Racl affects synaptic plasticity, attenuates learning-induced increases of Gadd $45 \mathrm{~b}$ and BDNF expression, and increases TGF- $\beta 1$ transcript (Fig. $8 D$ ). These changes in the mature neurons specifically prevent the learning-evoked increase in proliferation of $\mathrm{Dcx}^{+} \mathrm{NPCs}$. This is potentially mediated by a failure to increase BDNF/Trk2B signaling in progenitor cells and/or by an increase in the number of NPCs that exit cell cycle (Fig. 8C). This suggests that progenitor cell extrinsic activity-dependent plasticity and consequent adaptations in neuronal gene expression are required for normal experience-evoked neurogenesis in the adult hippocampus.
A recent study by Vadodaria et al. (2013) has demonstrated that cell-autonomous loss of Rac1 in the NPCs alters proliferation of NPCs in vitro, but has no effect on NP cell proliferation in naive mice in vivo. We showed that epidermal growth factor (EGF)-driven proliferation of NPC culture required Rac1 activity in vitro, whereas proliferation with fibroblast growth factor (FGF2) alone did not. We hypothesize that NPC proliferation within the in vivo adult dentate niche might not be induced by EGF signaling and hence loss of Rac1 in NPCs would not affect proliferation.

Our findings suggests that Racl in neurons is important for neurogenesis but our data also shows that loss of neuronal Rac1 has little effect on the signaling networks that maintain basal neurogenesis in animals housed in an unchanging and predictable environment. It is well recognized that changes or enrichment in the animals' environment increases the abundance of newborn neurons (van Praag et al., 2000; Kempermann et al., 2010) and that the act of learning itself can selectively stimulate the proliferation and survival of newly generated neurons (Shors, 2008; Shors et al., 2012). Under these conditions, neuronal Rac1 is required for at least a subset of signaling events that promote an increase in the accumulation of new neurons. We also show here that Racl expression is significantly increased in NPCs during learning (Fig. $1 F$ ), and one might speculate that a higher abundance of Racl in NPCs might raise Racl signaling thresholds 


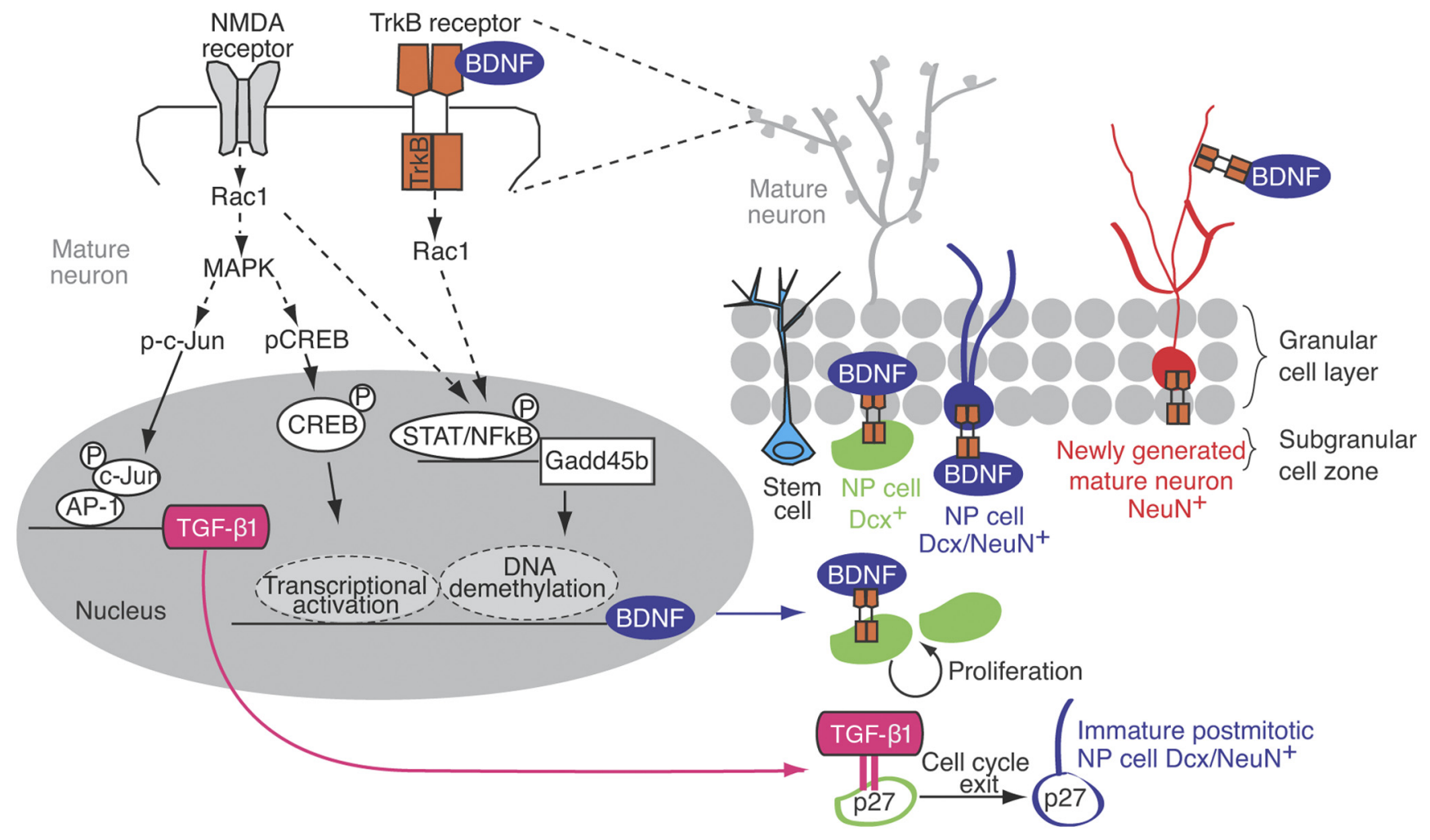

Figure 9. A simplified model of Rac1 signaling and function in learning-induced adult neurogenesis. Loss of Rac1 function in the mature neurons of the granule cell layer changes synaptic plasticity and impairs activity-induced transcriptional changes such as the upregulation of Gadd45b and BDNF. These transient changes in the mature neurons lead to long-lasting modifications of adult neurogenesis. Neuronal activation of mature dentate granule cells induces Rac1 activity through the NMDA receptor and the TrkB receptor. Rac1 triggers activation of multiple downstream pathways including (1) the mitogen activate protein MAPK pathway, which induces expression of TGF- $\beta 1$ and BDNF via c-Jun and CREB, respectively and (2) the STAT/NF $\kappa$ B-Gadd45b pathway (Balliet et al., 2001; Hoffman and Liebermann, 2009) leading to BDNF expression (Ma et al., 2009a). Loss of Rac1 in mature neurons lowers learning-induced increases of Gadd45b and BDNF expression, but increases TGF- $\beta 1$ expression. The secreted extrinsic factors from mature neurons in turn regulate several key aspects of adult neurogenesis over the long term. BDNF is known to promote proliferation, whereas TGF- $\beta 1$ is known to upregulate p27 Kip1, which would lead to increased cell cycle exit within the NPC and reduce overall NPC proliferation (Kandasamy et al., 2010). NMDA receptor, $N$-methyl-D-aspartate receptor; TrkB, tropomyosin-related kinase B; MAPK, mitogen activate protein kinase family; CREB, cAMP response element-binding protein, Gadd45b, growth arrest and DNA-damage-inducible beta; p27 Kip1, cyclin-dependent kinase inhibitor p27; NF $\kappa$ B, nuclear factor $\kappa$-light-chain-enhancer of activated B-cells.

above those necessary to intrinsically regulate cell cycle in NPCs in vivo.

Neuronal Rac1 appears to be specifically necessary for the increase in proliferation during learning itself. When Rac1 signaling is attenuated in neurons, then Racl-independent induction of neurogenesis such as running or AMPA receptor potentiation can be used to compensate for the lack of activity-dependent recruitment of new neurons. We have not determined the molecular mechanisms of Cx546-induced increase in $\mathrm{Dcx}^{+}$precursor cell number, but it is conceivable that the effects are accomplished through increased neuronal activity in the remaining Rac1-compentent neurons, increased synaptic plasticity (we did observe increased PSD- $95^{+}$spine numbers), and/or by directly activating $\mathrm{Dcx}^{+}$NPCs themselves.

The observed reduction of proliferation in Racl mutant mice during learning might result form (1) a slower proliferation rate (i.e., a prolonged cell cycle); (2) lower numbers of proliferationcompetent NPC/stem cells; or (3) a shift from the proliferative status to quiescence. We and others have previously shown that elevated levels of TGF- $\beta 1$ inhibit proliferation in the adult hippocampus in vivo (Buckwalter et al., 2006; Wachs et al., 2006). This is thought to occur at least in part by inducing cell cycle exit to quiescence (Kandasamy et al., 2010). Our findings of fewer proliferative NPCs during learning as well as a reduction in the fraction of cells that were recruited from the previously dividing pool of progenitors (Fig. $4 F$ ) support the latter two hypotheses.
Running before learning also reduced $\mathrm{p} 27 \mathrm{Kip} 1$ and TGF- $\beta 1$ transcript levels in mutant mice to the levels found in control runner-learners (Fig. 8A,D). Since learning-induced neurogenesis draws heavily on precursor cells that were dividing just before learning, it is possible that running in Racl mutants may simply increase the number of NPCs within the actively dividing pool, thus allowing a sufficient number of cells to be produced during learning to compensate for the lack of activity-dependent recruitment in mutant animals. Our data do support a simple correlation between the abundance of new neurons produced during learning and learning performance. It is too speculative to assume a causative correlation, but the association does indicate that recruitment of new cell formation during learning is a sensitive marker of hippocampal integrity and function.

Our data also suggest that the known Rac1-mediated elevation in MAP kinase signaling as well as activity-induced expression of Gadd45b and consequent upregulation of growth and trophic factors, such as BDNF, may underlie the learninginduced proliferative response (Fig. 9). BDNF signaling through neuronal Racl may itself synergize in this process to reinforce expression of activity-dependent neuronal genes. A consequence of defects in Rac1 signaling is a failure to downregulate TGF- $\beta 1$ and p27 Kip1 during learning (Fig. 9). This would prevent activity-dependent signaling from disinhibiting proliferation and maintain pressure to exit the cycle into differentiated or quiescent states. Our findings also suggest that running before learning can 
overcome this defect through mechanisms that are independent of activity-induced signaling through neuronal Rac1.

In combination, our findings suggest that experience-induced alterations in neurogenesis can be resolved into two distinct effects. The first one involves the well documented but Rac1independent signaling cascade that enhances the survival of young postmitotic neurons. The second mechanism influences neurogenesis through a Racl-dependent signaling pathway that is selectively important for learning-evoked synaptic changes and the consequent neurogenic zone adaptations that stimulate an increase in the abundance of proliferative progenitor cells.

\section{References}

Aimone JB, Wiles J, Gage FH (2006) Potential role for adult neurogenesis in the encoding of time in new memories. Nat Neurosci 9:723-727. CrossRef Medline

Ammanamanchi S, Tillekeratne MP, Ko TC, Brattain MG (2004) Endogenous control of cell cycle progression by autocrine transforming growth factor beta in breast cancer cells. Cancer Res 64:2509-2515. CrossRef Medline

Anderson ML, Sisti HM, Curlik DM 2nd, Shors TJ (2011) Associative learning increases adult neurogenesis during a critical period. Eur J Neurosci 33:175-181. CrossRef Medline

Arai AC, Kessler M (2007) Pharmacology of ampakine modulators: from AMPA receptors to synapses and behavior. Curr Drug Targets 8:583-602. CrossRef Medline

Babu H, Cheung G, Kettenmann H, Palmer TD, Kempermann G (2007) Enriched monolayer precursor cell cultures from micro-dissected adult mouse dentate gyrus yield functional granule cell-like neurons. PLoS One 2:e388. CrossRef Medline

Babu H, Claasen JH, Kannan S, Rünker AE, Palmer T, Kempermann G (2011) A protocol for isolation and enriched monolayer cultivation of neural precursor cells from mouse dentate gyrus. Front Neurosci 5:89. Medline

Balliet AG, Hatton KS, Hoffman B, Liebermann DA (2001) Comparative analysis of the genetic structure and chromosomal location of the murine MyD118 (Gadd45beta) gene. DNA Cell Biol 20:239-247. CrossRef Medline

Buckwalter MS, Yamane M, Coleman BS, Ormerod BK, Chin JT, Palmer T, Wyss-Coray T (2006) Chronically increased transforming growth factor-betal strongly inhibits hippocampal neurogenesis in aged mice. Am J Pathol 169:154-164. CrossRef Medline

Buongiorno P, Pethe VV, Charames GS, Esufali S, Bapat B (2008) Rac1 GTPase and the Racl exchange factor Tiaml associate with Wntresponsive promoters to enhance beta-catenin/TCF-dependent transcription in colorectal cancer cells. Mol Cancer 7:73. CrossRef Medline

Castilla-Ortega E, Pedraza C, Estivill-Torrús G, Santín LJ (2011) When is adult hippocampal neurogenesis necessary for learning? evidence from animal research. Rev Neurosci 22:267-283. Medline

Choi SH, Li Y, Parada LF, Sisodia SS (2009) Regulation of hippocampal progenitor cell survival, proliferation and dendritic development by BDNF. Mol Neurodegener 4:52. CrossRef Medline

Chrostek A, Wu X, Quondamatteo F, Hu R, Sanecka A, Niemann C, Langbein L, Haase I, Brakebusch C (2006) Racl is crucial for hair follicle integrity but is not essential for maintenance of the epidermis. Mol Cell Biol 26: 6957-6970. CrossRef Medline

Corsini NS, Sancho-Martinez I, Laudenklos S, Glagow D, Kumar S, Letellier E, Koch P, Teodorczyk M, Kleber S, Klussmann S, Wiestler B, Brüstle O, Mueller W, Gieffers C, Hill O, Thiemann M, Seedorf M, Gretz N, Sprengel $\mathrm{R}$, Celikel T, et al. (2009) The death receptor CD95 activates adult neural stem cells for working memory formation and brain repair. Cell Stem Cell 5:178-190. CrossRef Medline

Curlik DM 2nd, Shors TJ (2011) Learning increases the survival of newborn neurons provided that learning is difficult to achieve and successful. J Cogn Neurosci 23:2159-2170. CrossRef Medline

Deisseroth K, Singla S, Toda H, Monje M, Palmer TD, Malenka RC (2004) Excitation-neurogenesis coupling in adult neural stem/progenitor cells. Neuron 42:535-552. CrossRef Medline

Deng W, Aimone JB, Gage FH (2010) New neurons and new memories: how does adult hippocampal neurogenesis affect learning and memory? Nat Rev Neurosci 11:339-350. CrossRef Medline
Diana G, Valentini G, Travaglione S, Falzano L, Pieri M, Zona C, Meschini S, Fabbri A, Fiorentini C (2007) Enhancement of learning and memory after activation of cerebral Rho GTPases. Proc Natl Acad Sci U S A 104: 636-641. CrossRef Medline

Döbrössy MD, Drapeau E, Aurousseau C, Le Moal M, Piazza PV, Abrous DN (2003) Differential effects of learning on neurogenesis: learning increases or decreases the number of newly born cells depending on their birth date. Mol Psychiatry 8:974-982. CrossRef Medline

Dupret D, Fabre A, Döbrössy MD, Panatier A, Rodríguez JJ, Lamarque S, Lemaire V, Oliet SH, Piazza PV, Abrous DN (2007) Spatial learning depends on both the addition and removal of new hippocampal neurons. PLoS Biol 5:e214. CrossRef Medline

Esufali S, Bapat B (2004) Cross-talk between Racl GTPase and dysregulated Wnt signaling pathway leads to cellular redistribution of beta-catenin and TCF/LEF-mediated transcriptional activation. Oncogene 23:8260-8271. CrossRef Medline

Ge S, Yang CH, Hsu KS, Ming GL, Song H (2007) A critical period for enhanced synaptic plasticity in newly generated neurons of the adult brain. Neuron 54:559-566. CrossRef Medline

Haditsch U, Leone DP, Farinelli M, Chrostek-Grashoff A, Brakebusch C, Mansuy IM, McConnell SK, Palmer TD (2009) A central role for the small GTPase Racl in hippocampal plasticity and spatial learning and memory. Mol Cell Neurosci 41:409-419. CrossRef Medline

Hoffman B, Liebermann DA (2009) Gadd45 modulation of intrinsic and extrinsic stress responses in myeloid cells. J Cell Physiol 218:26-31. CrossRef Medline

Jeltsch H, Bertrand F, Lazarus C, Cassel JC (2001) Cognitive performances and locomotor activity following dentate granule cell damage in rats: role of lesion extent and type of memory tested. Neurobiol Learn Mem 76:81105. CrossRef Medline

Kandasamy M, Couillard-Despres S, Raber KA, Stephan M, Lehner B, Winner B, Kohl Z, Rivera FJ, Nguyen HP, Riess O, Bogdahn U, Winkler J, von Hörsten S, Aigner L (2010) Stem cell quiescence in the hippocampal neurogenic niche is associated with elevated transforming growth factorbeta signaling in an animal model of Huntington disease. J Neuropathol Exp Neurol 69:717-728. CrossRef Medline

Kempermann G, Fabel K, Ehninger D, Babu H, Leal-Galicia P, Garthe A, Wolf SA (2010) Why and how physical activity promotes experience-induced brain plasticity. Front Neurosci 4:189. Medline

Kowalczyk A, Filipkowski RK, Rylski M, Wilczynski GM, Konopacki FA, Jaworski J, Ciemerych MA, Sicinski P, Kaczmarek L (2004) The critical role of cyclin D2 in adult neurogenesis. J Cell Biol 167:209-213. CrossRef Medline

Kubiczkova L, Sedlarikova L, Hajek R, Sevcikova S (2012) TGF-beta -an excellent servant but a bad master. J Transl Med 10:183. CrossRef Medline

Kwei KA, Finch JS, Ranger-Moore J, Bowden GT (2006) The role of Racl in maintaining malignant phenotype of mouse skin tumor cells. Cancer Lett 231:326-338. CrossRef Medline

Lauterborn JC, Lynch G, Vanderklish P, Arai A, Gall CM (2000) Positive modulation of AMPA receptors increases neurotrophin expression by hippocampal and cortical neurons. J Neurosci 20:8-21. Medline

Lee E, Son H (2009) Adult hippocampal neurogenesis and related neurotrophic factors. BMB Rep 42:239-244. CrossRef Medline

Luo L (2000) Rho GTPases in neuronal morphogenesis. Nat Rev Neurosci 1:173-180. CrossRef Medline

Ma DK, Kim WR, Ming GL, Song H (2009a) Activity-dependent extrinsic regulation of adult olfactory bulb and hippocampal neurogenesis. Ann N Y Acad Sci 1170:664-673. CrossRef Medline

Ma DK, Jang MH, Guo JU, Kitabatake Y, Chang ML, Pow-Anpongkul N, Flavell RA, Lu B, Ming GL, Song H (2009b) Neuronal activity-induced Gadd45b promotes epigenetic DNA demethylation and adult neurogenesis. Science 323:1074-1077. CrossRef Medline

Ma DK, Marchetto MC, Guo JU, Ming GL, Gage FH, Song H (2010) Epigenetic choreographers of neurogenesis in the adult mammalian brain. Nat Neurosci 13:1338-1344. CrossRef Medline

Martinez LA, Klann E, Tejada-Simon MV (2007) Translocation and activation of Rac in the hippocampus during associative contextual fear learning. Neurobiol Learn Mem 88:104-113. CrossRef Medline

Minden A, Lin A, Claret FX, Abo A, Karin M (1995) Selective activation of the JNK signaling cascade and c-Jun transcriptional activity by the small GTPases Rac and Cdc42Hs. Cell 81:1147-1157. CrossRef Medline

Morris RG, Frey U (1997) Hippocampal synaptic plasticity: role in spatial 
learning or the automatic recording of attended experience? Philos Trans R Soc Lond B Biol Sci 352:1489-1503. CrossRef Medline

Nakayama AY, Harms MB, Luo L (2000) Small GTPases Rac and Rho in the maintenance of dendritic spines and branches in hippocampal pyramidal neurons. J Neurosci 20:5329-5338. Medline

Novak A, Guo C, Yang W, Nagy A, Lobe CG (2000) Z/EG, a double reporter mouse line that expresses enhanced green fluorescent protein upon Cremediated excision. Genesis 28:147-155. CrossRef Medline

Palmer TD, Schwartz PH, Taupin P, Kaspar B, Stein SA, Gage FH (2001) Cell culture. Progenitor cells from human brain after death. Nature 411: 42-43. CrossRef Medline

Sairanen M, Lucas G, Ernfors P, Castren M, Castrén E (2005) Brain-derived neurotrophic factor and antidepressant drugs have different but coordinated effects on neuronal turnover, proliferation, and survival in the adult dentate gyrus. J Neurosci 25:1089-1094. CrossRef Medline

Schweizer C, Balsiger S, Bluethmann H, Mansuy IM, Fritschy JM, Mohler H, Lüscher B (2003) The gamma 2 subunit of GABA(A) receptors is required for maintenance of receptors at mature synapses. Mol Cell Neurosci 24:442-450. CrossRef Medline

Shors TJ (2008) From stem cells to grandmother cells: how neurogenesis relates to learning and memory. Cell Stem Cell 3:253-258. CrossRef Medline

Shors TJ, Miesegaes G, Beylin A, Zhao M, Rydel T, Gould E (2001) Neurogenesis in the adult is involved in the formation of trace memories. Nature 410:372-376. CrossRef Medline

Shors TJ, Anderson ML, Curlik DM 2nd, Nokia MS (2012) Use it or lose it: how neurogenesis keeps the brain fit for learning. Behav Brain Res 227: 450-458. CrossRef Medline

Soriano P (1999) Generalized lacZ expression with the ROSA26 Cre reporter strain. Nat Genet 21:70-71. CrossRef Medline

Steele RJ, Morris RG (1999) Delay-dependent impairment of a matchingto-place task with chronic and intrahippocampal infusion of the NMDAantagonist D-AP5. Hippocampus 9:118-136. CrossRef Medline

Sutherland RJ, Whishaw IQ, Kolb B (1983) A behavioural analysis of spatial localization following electrolytic, kainate- or colchicine-induced damage to the hippocampal formation in the rat. Behav Brain Res 7:133-153. CrossRef Medline

Tashiro A, Yuste R (2004) Regulation of dendritic spine motility and stability by Racl and Rho kinase: evidence for two forms of spine motility. Mol Cell Neurosci 26:429-440. CrossRef Medline

Tashiro A, Yuste R (2008) Role of Rho GTPases in the morphogenesis and motility of dendritic spines. Methods Enzymol 439:285-302. CrossRef Medline

Tashiro A, Minden A, Yuste R (2000) Regulation of dendritic spine morphology by the rho family of small GTPases: antagonistic roles of Rac and Rho. Cereb Cortex 10:927-938. CrossRef Medline

Tejada-Simon MV, Villasana LE, Serrano F, Klann E (2006) NMDA receptor activation induces translocation and activation of Rac in mouse hippocampal area CA1. Biochem Biophys Res Commun 343:504-512. CrossRef Medline

Tronel S, Fabre A, Charrier V, Oliet SH, Gage FH, Abrous DN (2010) Spatial learning sculpts the dendritic arbor of adult-born hippocampal neurons. Proc Natl Acad Sci U S A 107:7963-7968. CrossRef Medline

Vadodaria KC, Brakebusch C, Suter U, Jessberger S (2013) Stage-specific functions of the small rho GTPases cdc42 and racl for adult hippocampal neurogenesis. J Neurosci 33:1179-1189. CrossRef Medline

van Praag H, Kempermann G, Gage FH (2000) Neural consequences of environmental enrichment. Nat Rev Neurosci 1:191-198. CrossRef Medline

Wachs FP, Winner B, Couillard-Despres S, Schiller T, Aigner R, Winkler J, Bogdahn U, Aigner L (2006) Transforming growth factor-betal is a negative modulator of adult neurogenesis. J Neuropathol Exp Neurol 65: 358-370. CrossRef Medline

Waddell J, Anderson ML, Shors TJ (2011) Changing the rate and hippocampal dependence of trace eyeblink conditioning: slow learning enhances survival of new neurons. Neurobiol Learn Mem 95:159-165. CrossRef Medline

Wiens KM, Lin H, Liao D (2005) Racl induces the clustering of AMPA receptors during spinogenesis. J Neurosci 25:10627-10636. CrossRef Medline

Wojtowicz JM (2008) Potential consequences of altered neurogenesis on learning and memory in the epileptic brain. Epilepsia 49 [Suppl 5]:42-49. CrossRef Medline

Xavier GF, Oliveira-Filho FJ, Santos AM (1999) Dentate gyrus-selective colchicine lesion and disruption of performance in spatial tasks: difficulties in "place strategy" because of a lack of flexibility in the use of environmental cues? Hippocampus 9:668-681. CrossRef Medline

Yang EJ, Yoon JH, Min DS, Chung KC (2004) LIM kinase 1 activates cAMPresponsive element-binding protein during the neuronal differentiation of immortalized hippocampal progenitor cells. J Biol Chem 279:89038910. CrossRef Medline 